Appendix IV: Photo log, in Krass, V.A., Vaitl, J.D., and Amoco Oil Co., 1986 Alaska fieldwork, Lisburne Peninsula and western De Long Mountains, Alaska

Krass, V.A., Vaitl, J.D., and Amoco Oil Co.

GMC DATA REPORT 459D

This GMC data report from the Amoco Heritage collection has been made available through funding from the FY2018 USGS National Geological and Geophysical Data Preservation Program, Grant Number G18AP00054. This project report is presented in its original format and has not been reviewed for technical content or for conformity to the editorial standards of DGGS. It should not be used or cited as reviewed data.

2019

State of Alaska

Department of Natural Resources

Division of Geological \& Geophysical Surveys

GEOLOGIC MATERIALS CENTER
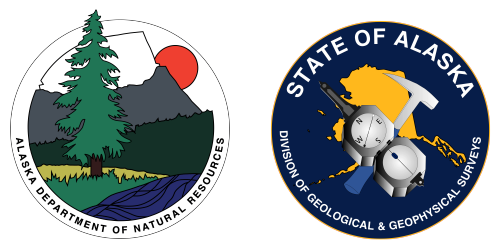


\section{APPENDIX IV}

1986 ALASKA FIELD WORK

LISBURNE PENINSULA - WEST BROOKS RANGE

PHOTO LOG

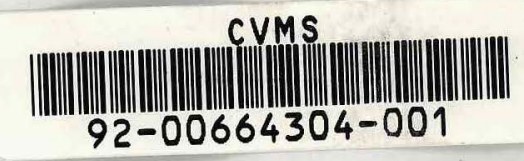




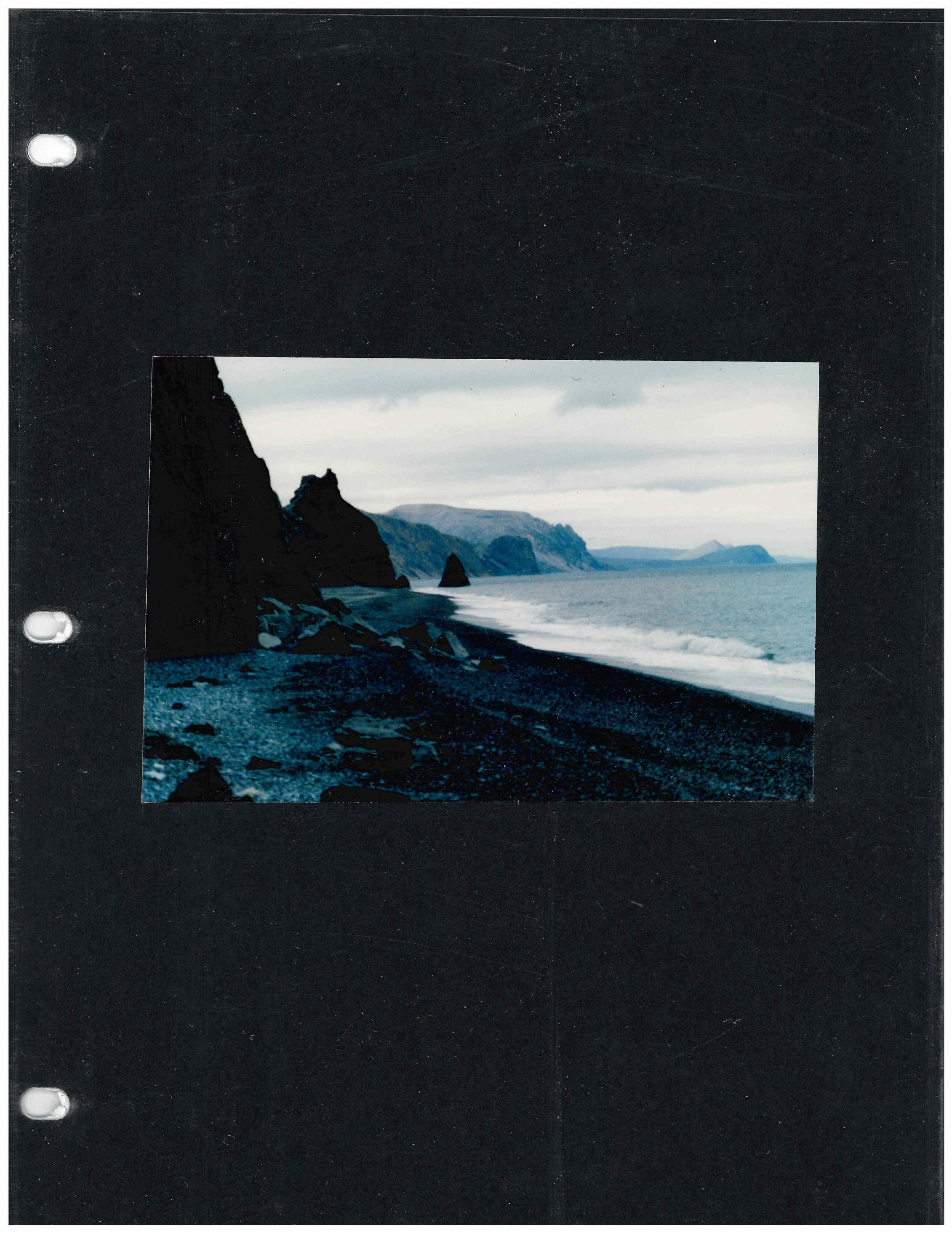


Coastal view north of Cape Dyer.

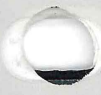




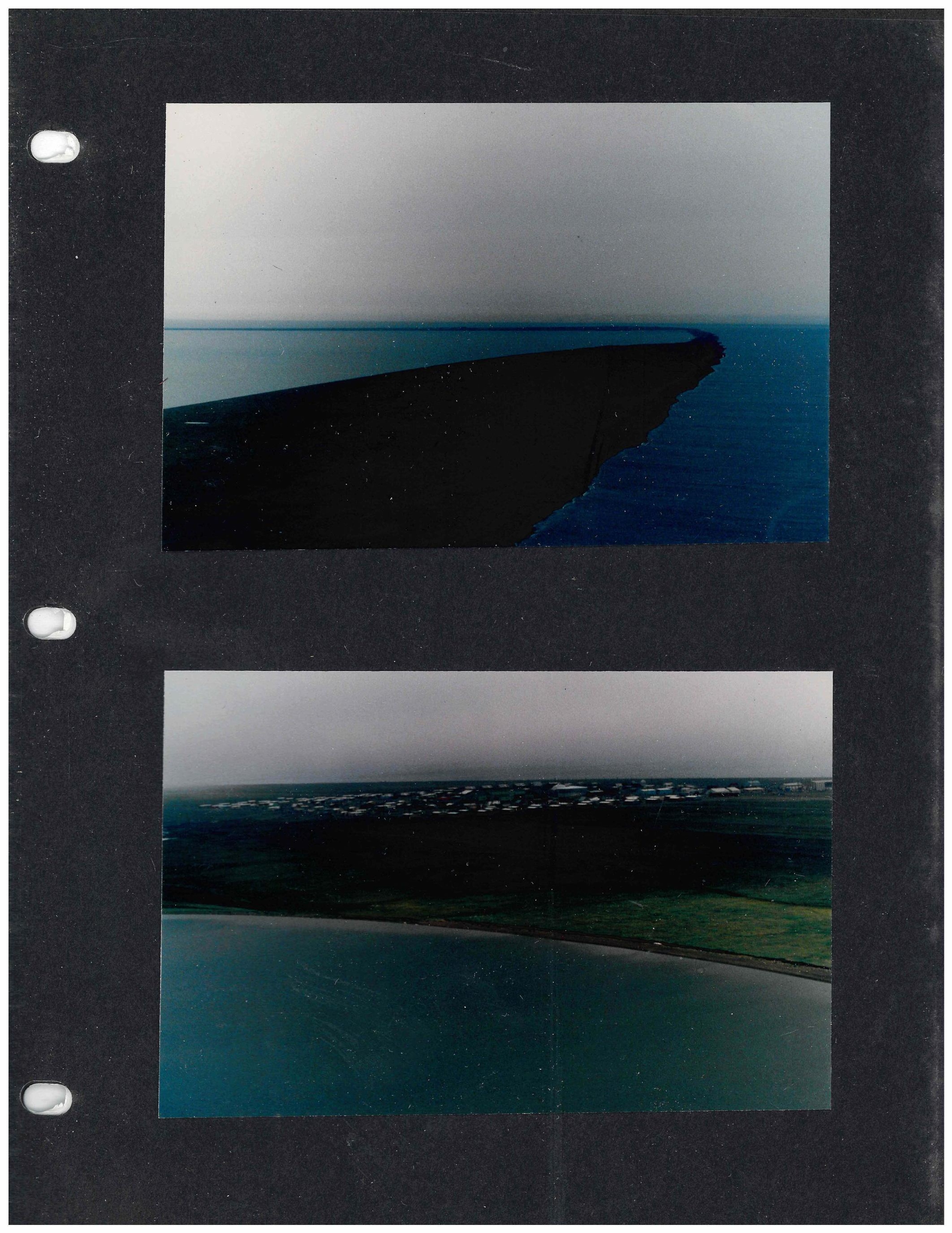


View of gravel beaches

looking west towards Point Hope.

Aerial view of Point Hope Village. 


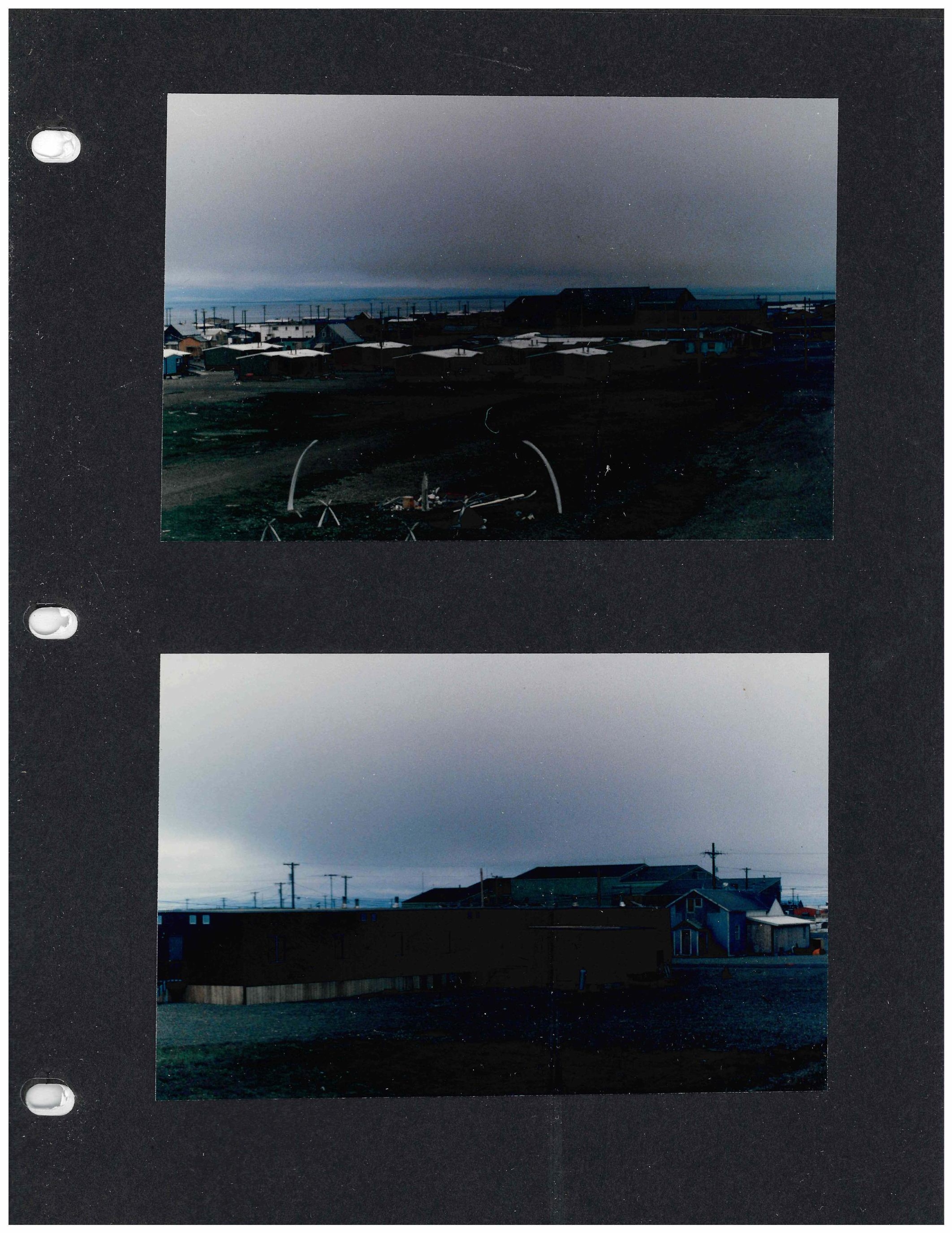


Aerial view of school and houses at Point Hope Village

Aerial view of hotel and old camp at Point Hope Village 


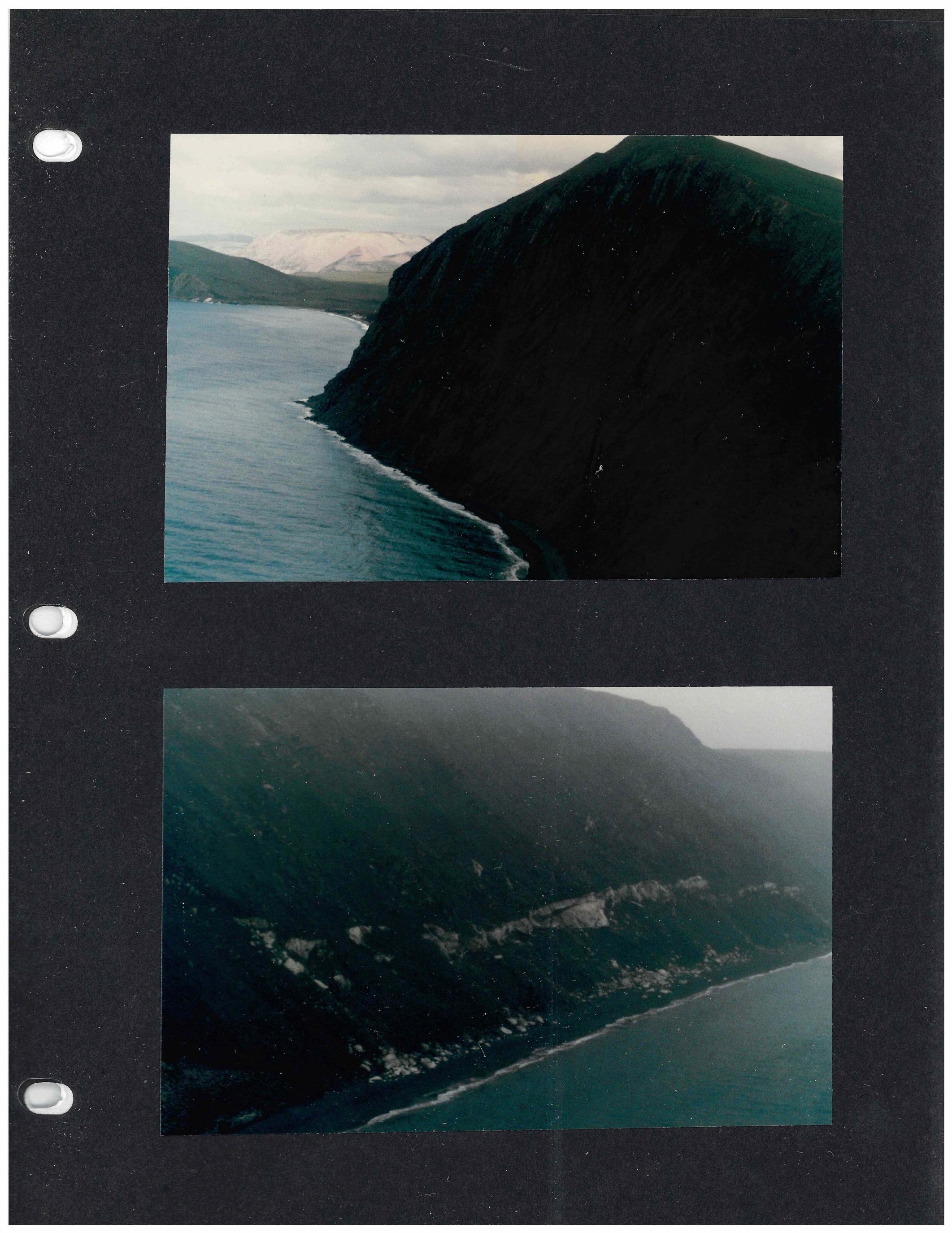


View of Silurian/Ordovician Cliffs.
Coastline TlOS-R6IW

Silurian/Ordovician clastics with large calcite vein. TIOS-R6IW 

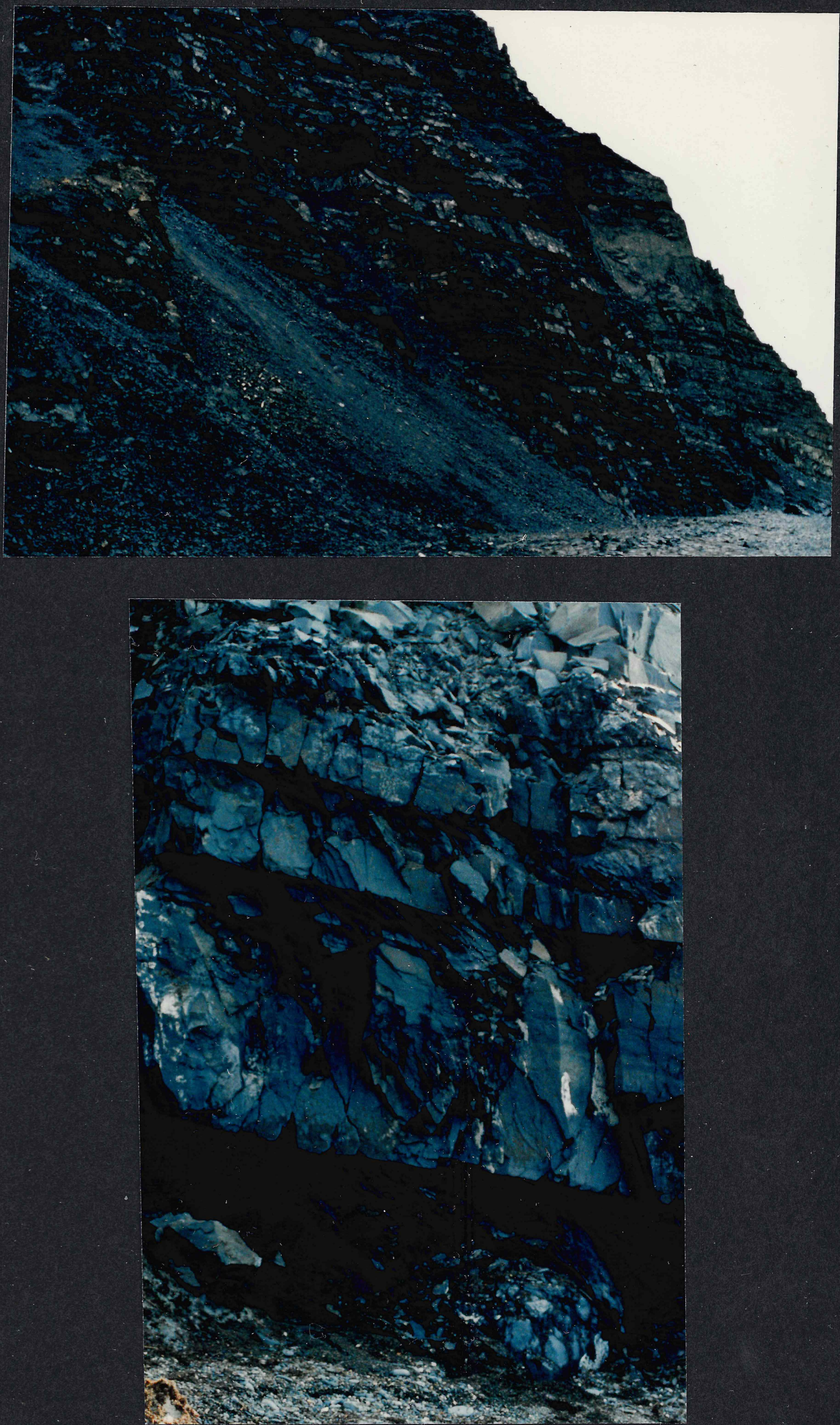
Silurian/Ordovician graywacke section.

Silurian/Ordovician section showing cleavage at high angle to bedding. 7/22-11

SW/4 19-T11S-R61W 


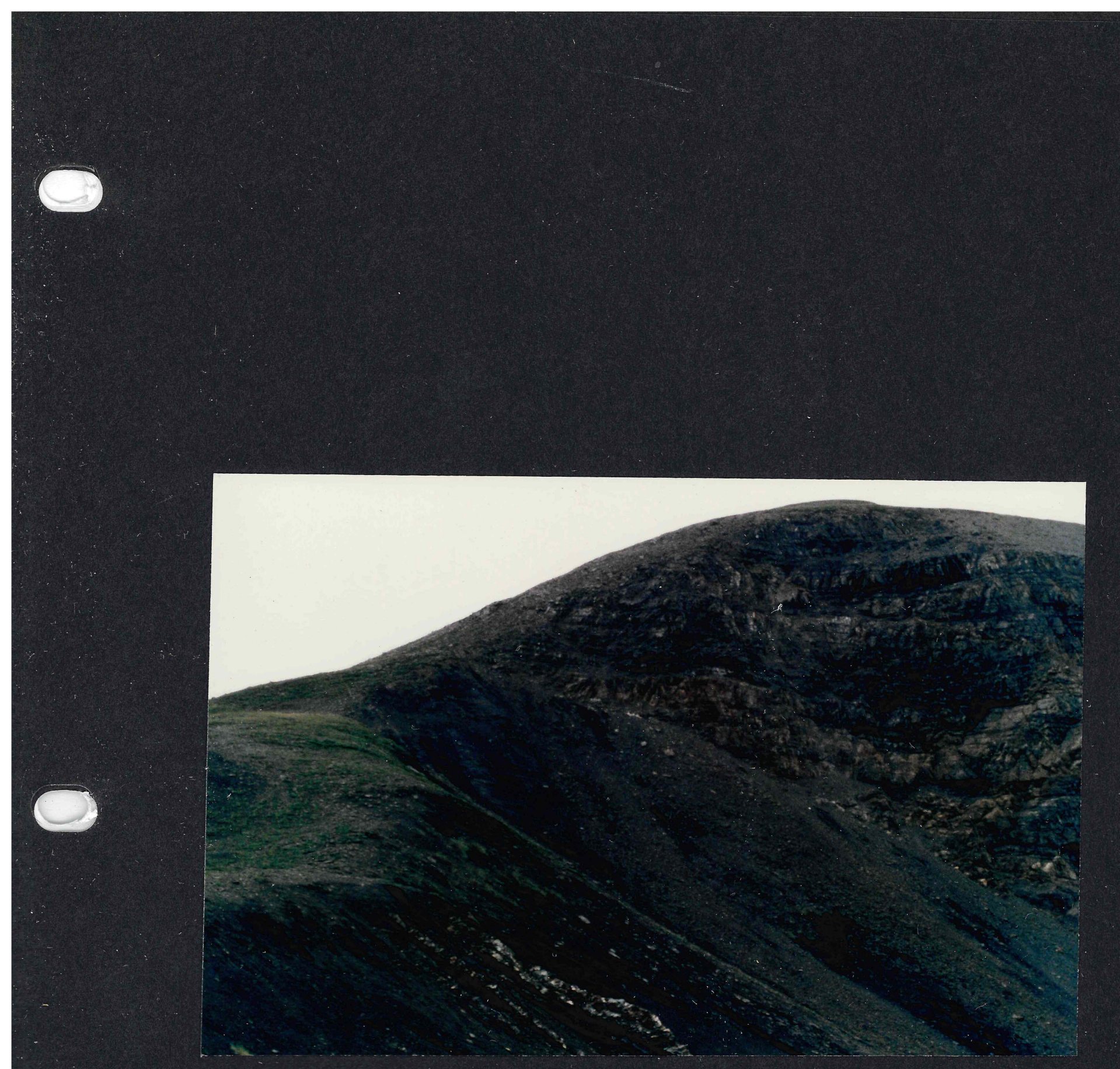


Cliff of Silurian/Ordovician graywacke and slope of black shale of uncertain age. $\mathrm{NE} / 4$ 33-T9S-R61W 

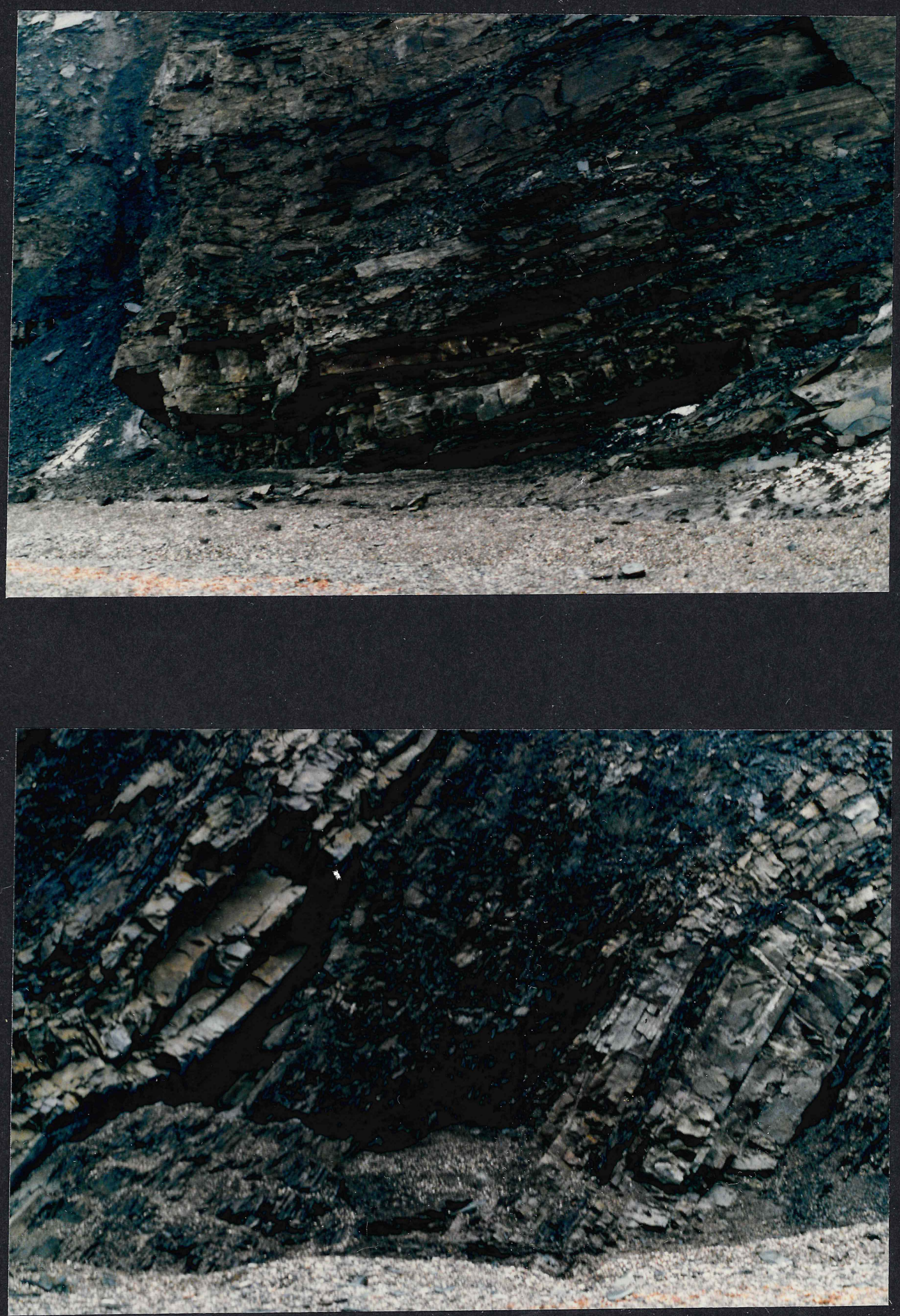


\section{Early Mississippian Endicott Group sand and shale. 7-19-1 $33-\mathrm{T} 9 \mathrm{~S}-61 \mathrm{~W}$}

Early Mississippian Endicott Group sand and shale. 7-19-1 $33-\mathrm{T} 9 \mathrm{~S}-\mathrm{R} 61 \mathrm{~W}$ 


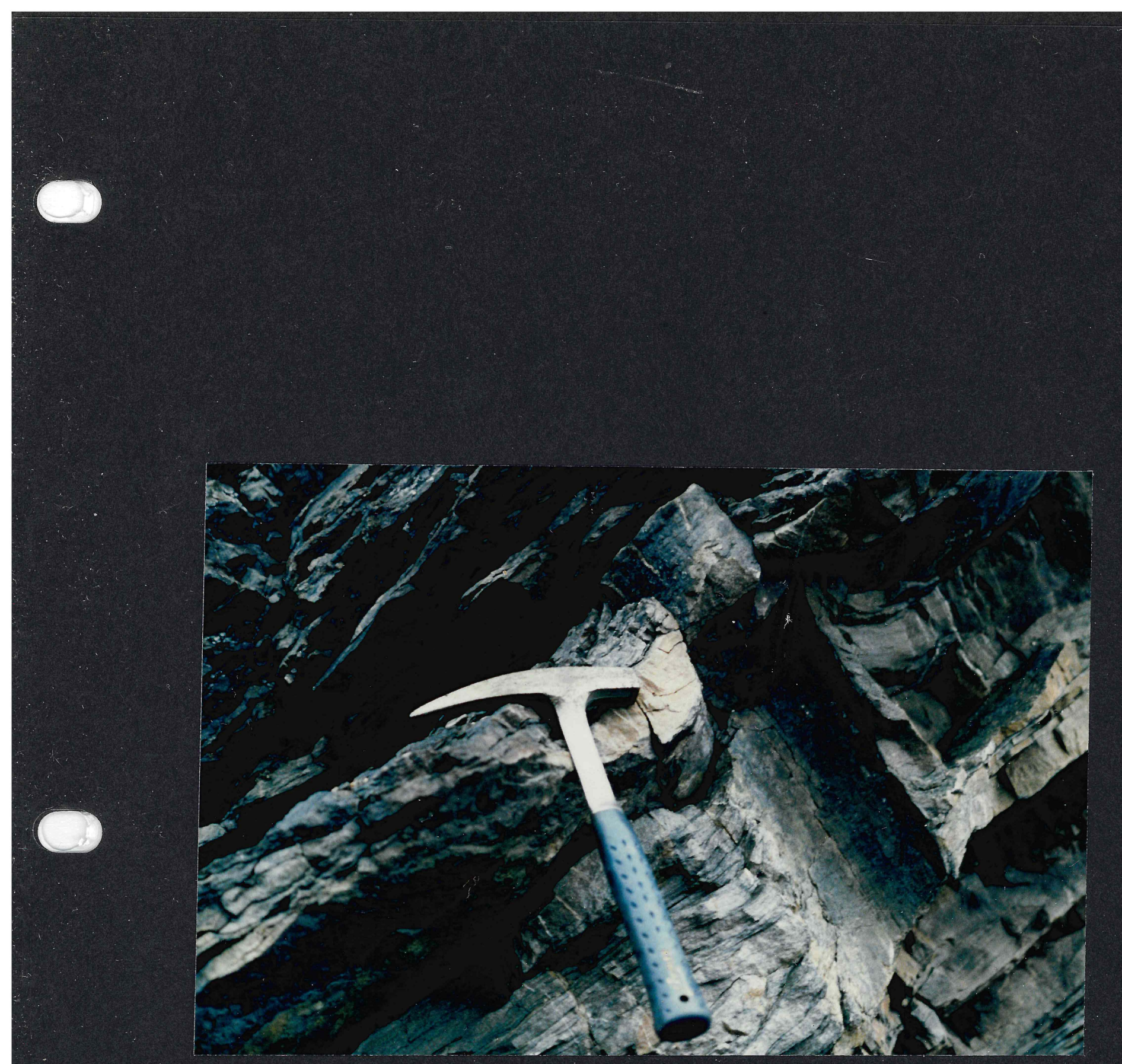


Early Mississippian Endicott Group showing upright tree mold. 7-19-1 $33-\not R 9 S-R 61 W$

$T$ 

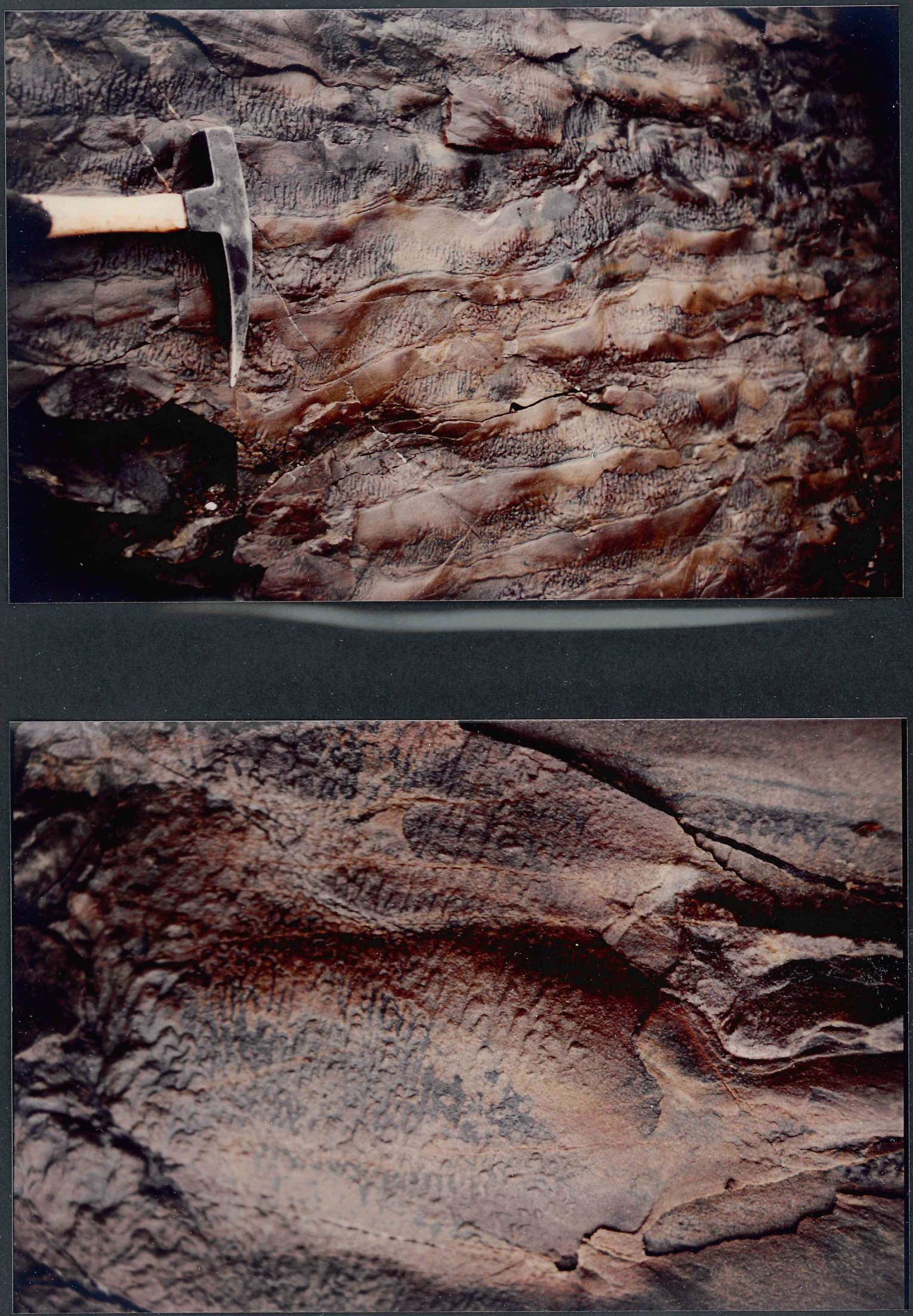
Endicott Group shale bedding plane showing large-scale ripples and

small-scale flute structures. 7-19-2

$W / 2 \quad 28-9 S-61 W$

Enlargement of above. 

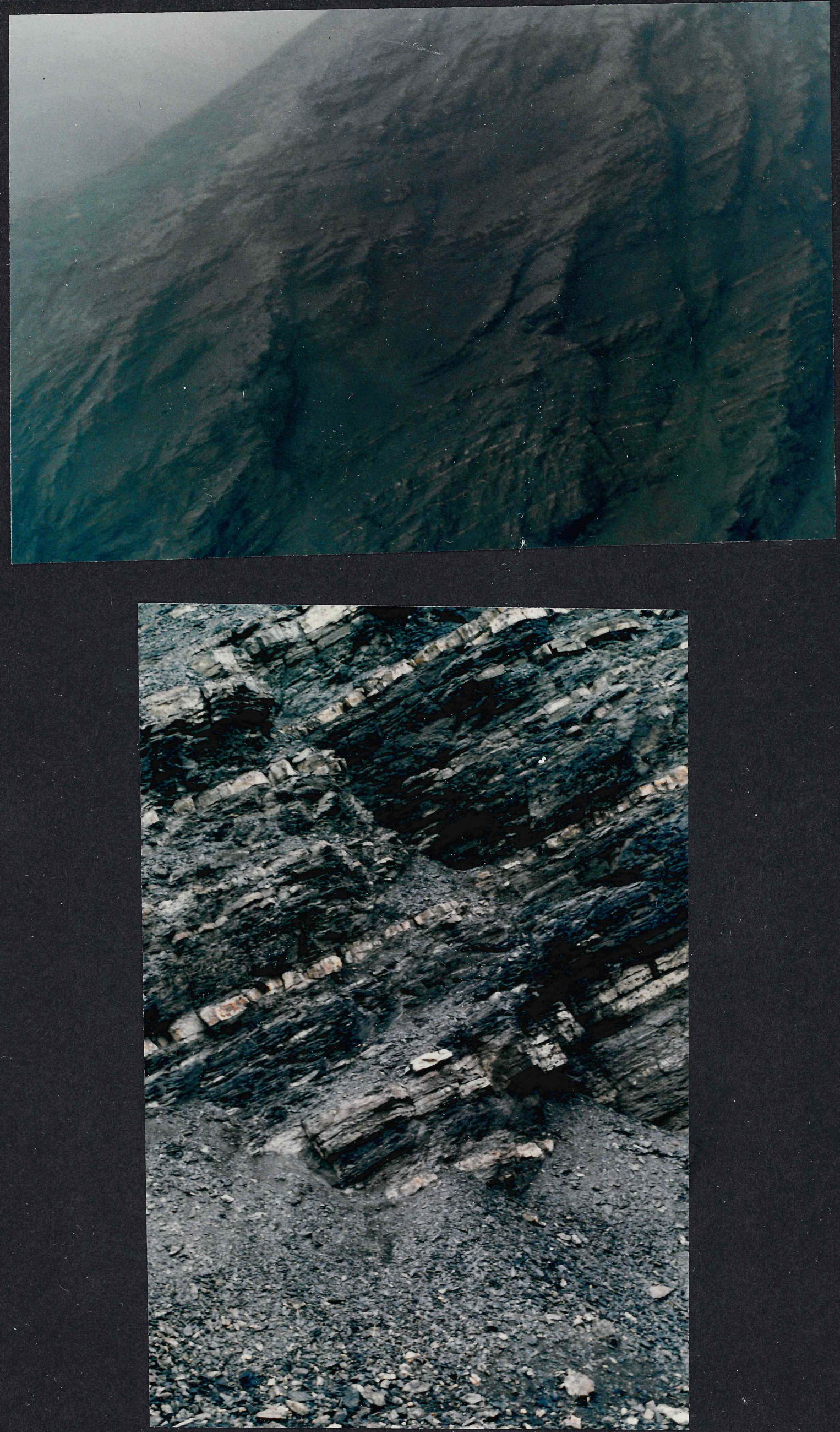


\section{Aerial view of Early Mississippian marine limestone and shale. 7-17-6 \\ $\mathrm{SE} / 4-27-32 \mathrm{~N}-32 \mathrm{~W}$}

Folded Early Mississippian marine limestone and shale. 

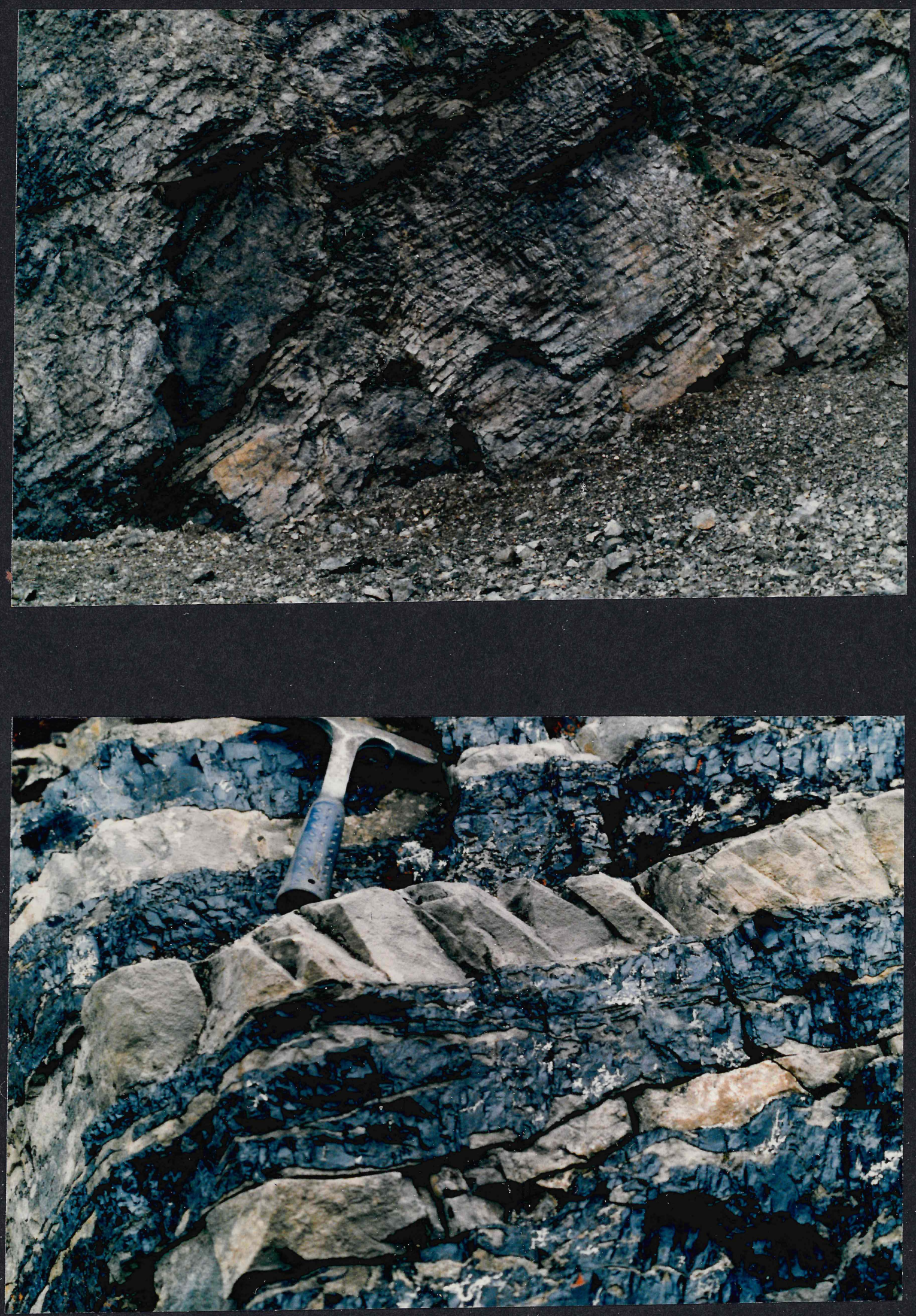
Kogruk Limestone, Mississippian Lisburne Group. 7/21-1 $\mathrm{SE} / 4 \quad 6-31 \mathrm{~N}-31 \mathrm{~W}$

Mississippian Kogruk Formation, Lisburne Group, interbedded chert and dolomite. 7-18-11

$\mathrm{NE} / 4 \quad 10-33 \mathrm{~N}-3 \mathrm{OW}$ 

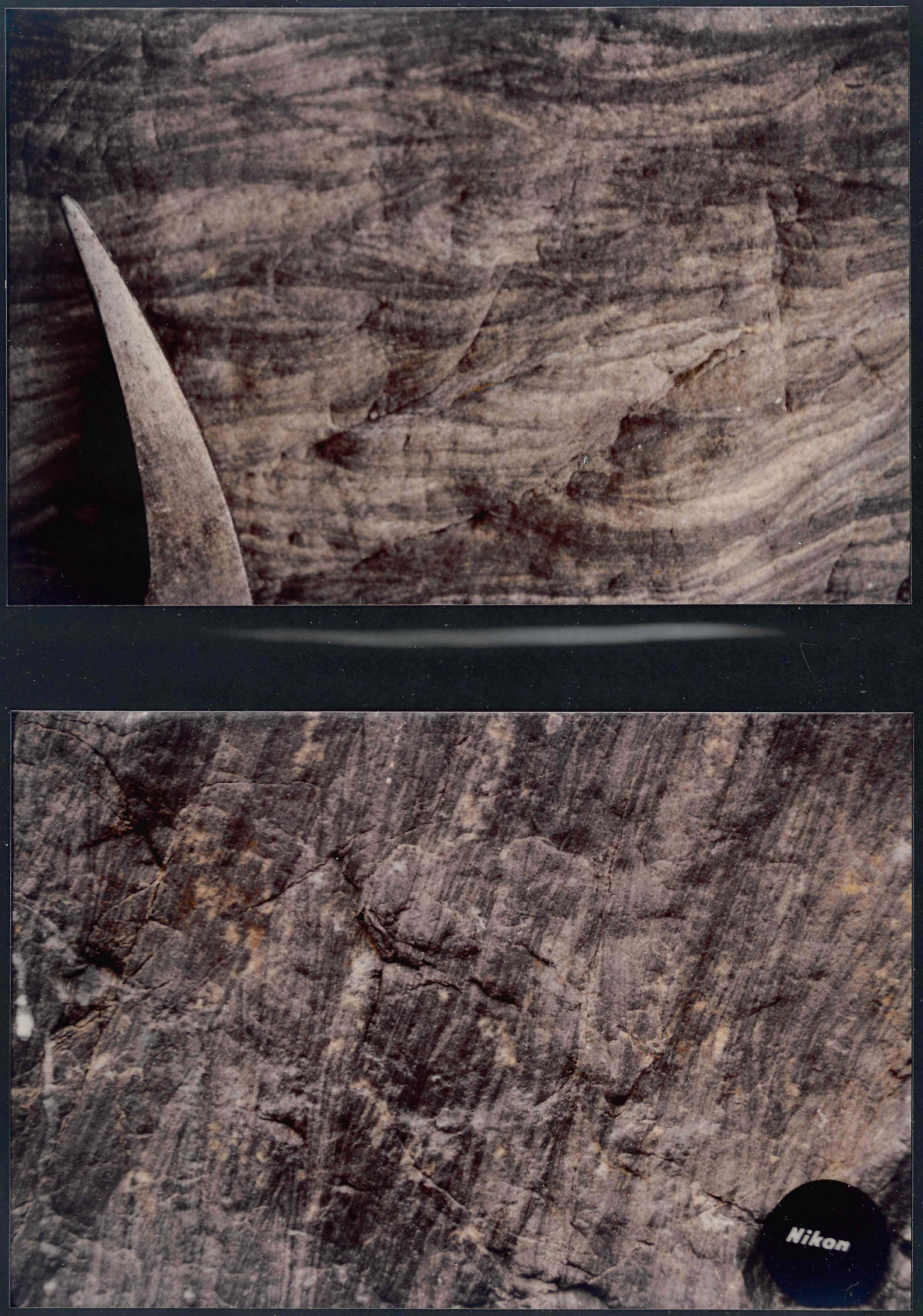
Kogruk Formation, Lisburne Group. Cross-bedding in finely laminated crystalline lime dolomite. 7-21-1 $\mathrm{SE} / 4 \quad 6-32 \mathrm{~N}-31 \mathrm{~W}$

Kogruk Formation, Lisburne Group. Small scale cross-bedding in finely laminated crysatline lime dolomite. 7-21-1

$\mathrm{SE} / 4 \quad 6-32 \mathrm{~N}-31 \mathrm{~W}$ 


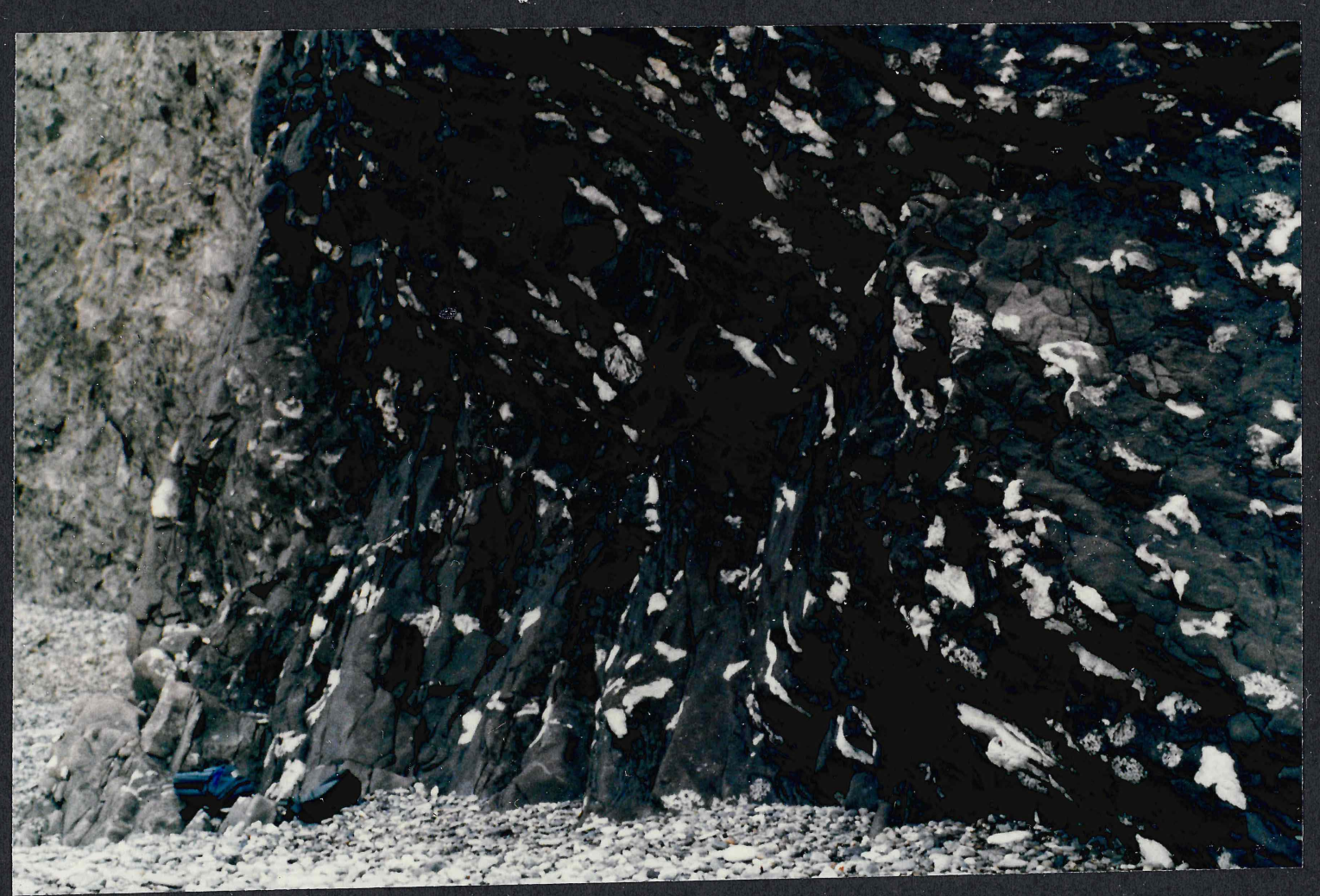


Lisburne Group coral beds. 7/22-2 NW/4 28-7S-60W 


\section{Lisburne Group coral beds. 7/22-2 $\mathrm{NW} / 4$ 28-7S-60W}

Lisburne Group hex coral head. 7/22-2 $\mathrm{NW} / 4 \quad 28-7 \mathrm{~S}-60 \mathrm{~W}$ 

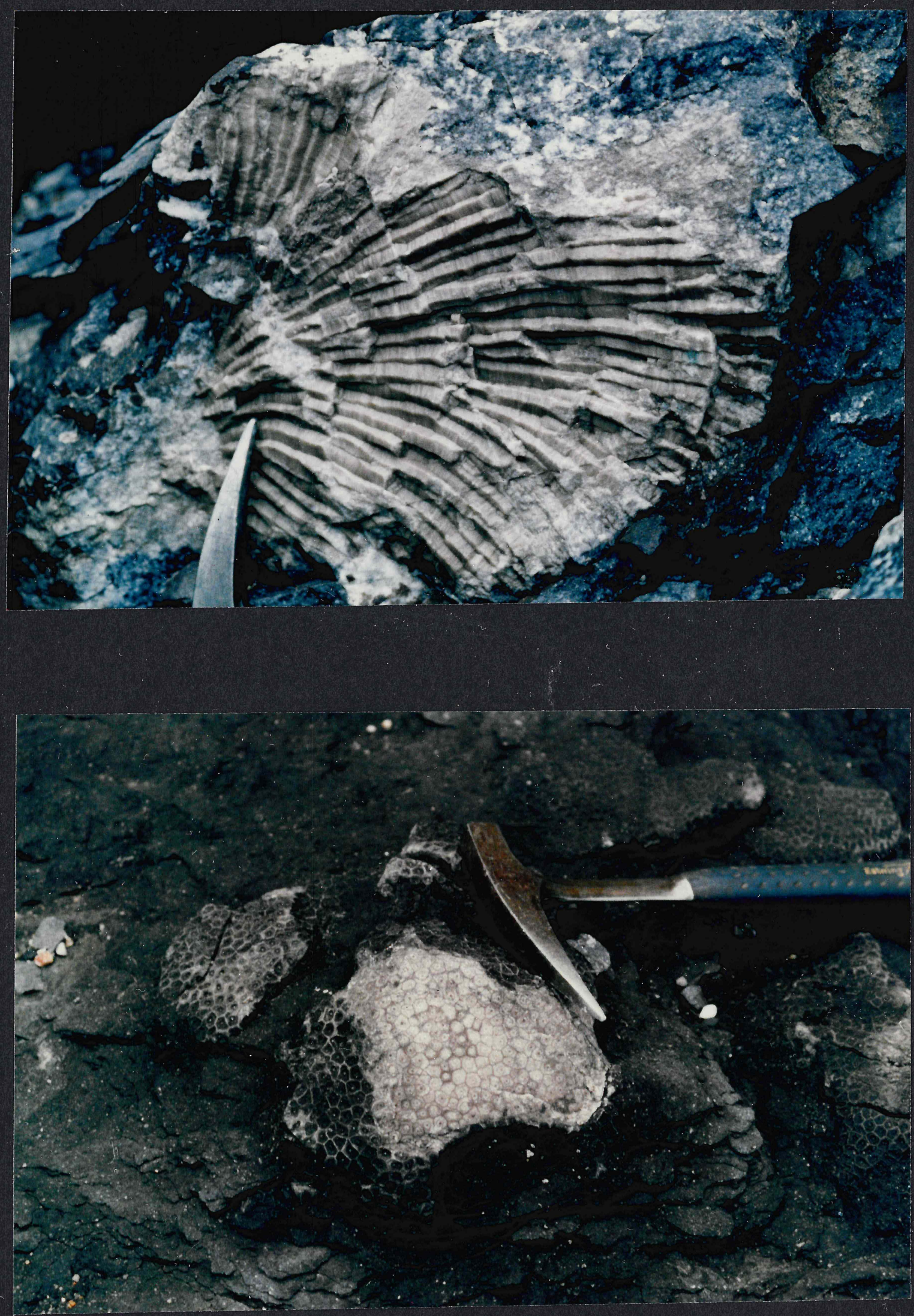
Mississippian Lisburne Group

hex coral head cross-section. 7/22-1

$\mathrm{E} / 217,20-7 \mathrm{~S}-60 \mathrm{~W}$

Lisburne Kogruk Formation hexagonal coral head. 7/22-1 $\mathrm{E} / 217,20-7 \mathrm{~S}-60 \mathrm{~W}$ 
Lisburne Group interbedded limestone and shale. 7/22-1 $\mathrm{E} / 2$ 17, 20-7S-60W 


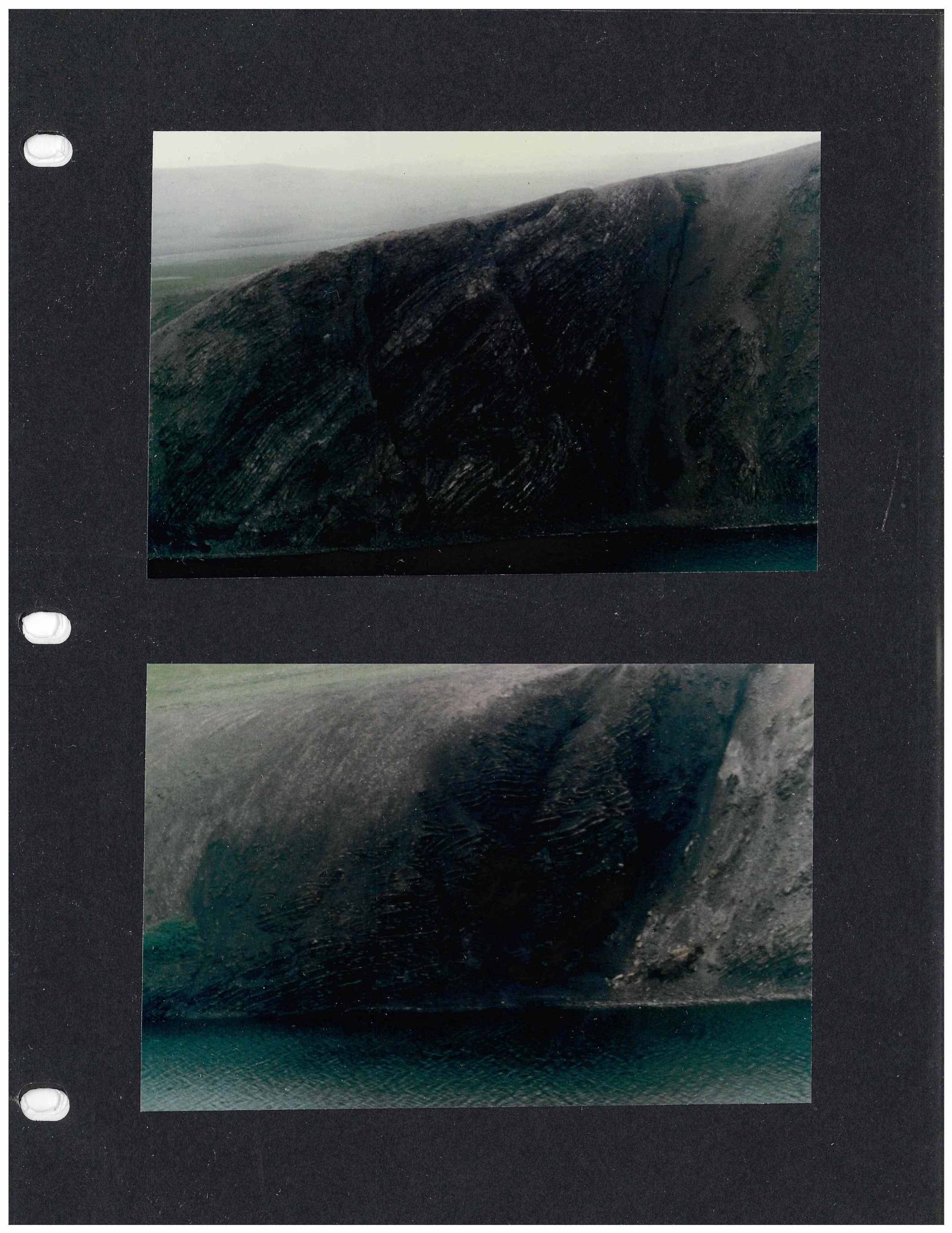


Mississippian Nasorak Formation, Lisburne Group, folded limestone and black shale. 7-18-15

$\mathrm{NE} / 4 \quad 18-34 \mathrm{~N}-30 \mathrm{~W}$

Mississippian Nasorak Formation, Lisburne Group, folded limestone and black shale. 7-18-15 $\mathrm{NE} / 4 \quad 18-34 \mathrm{~N}-30 \mathrm{~W}$ 


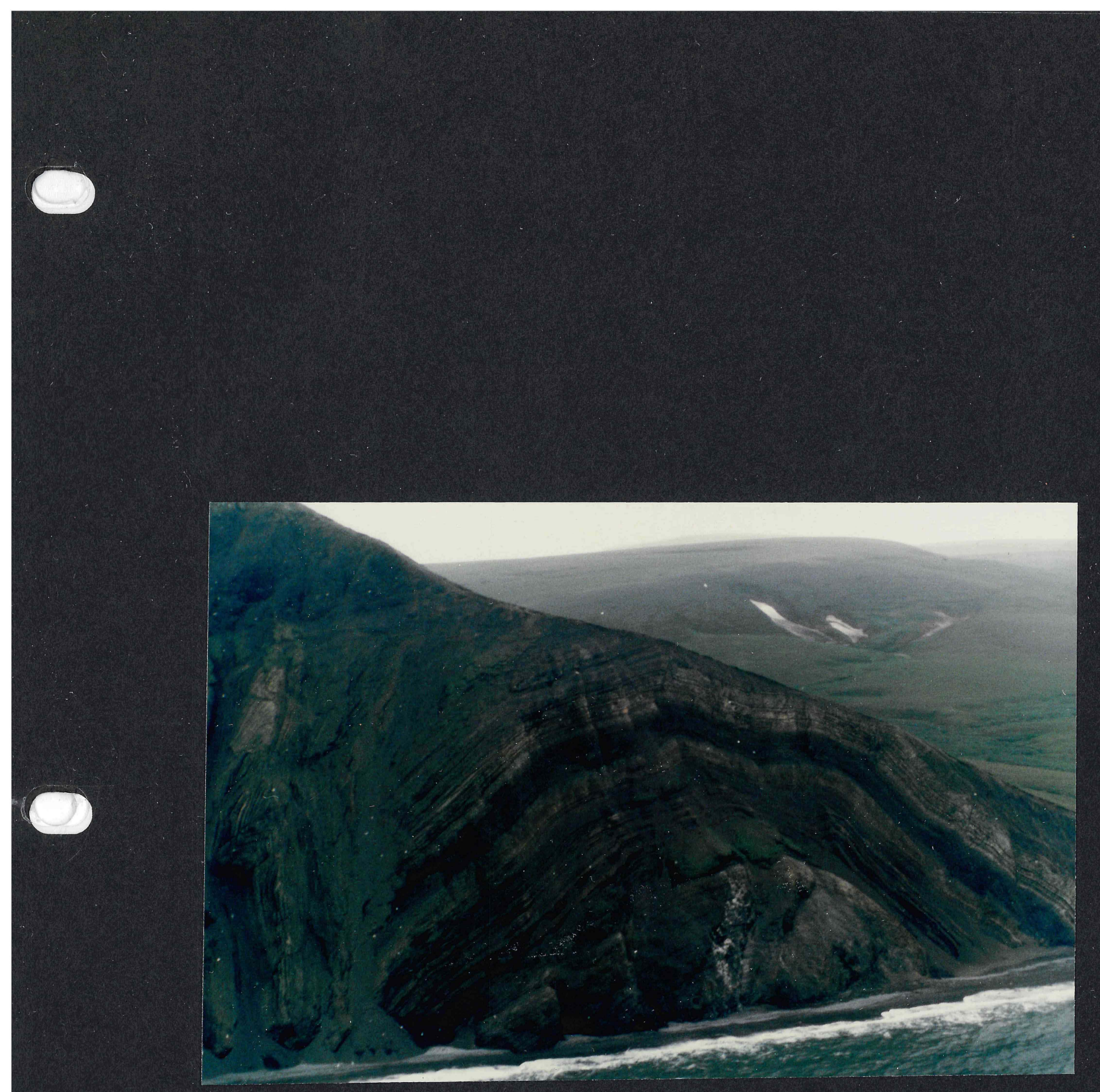


Aerial view of Permo-Triassic Agate Rock. $\mathrm{SW} / 4 \mathrm{~T} 32 \mathrm{~N}, \mathrm{R} 32 \mathrm{~W}$ 


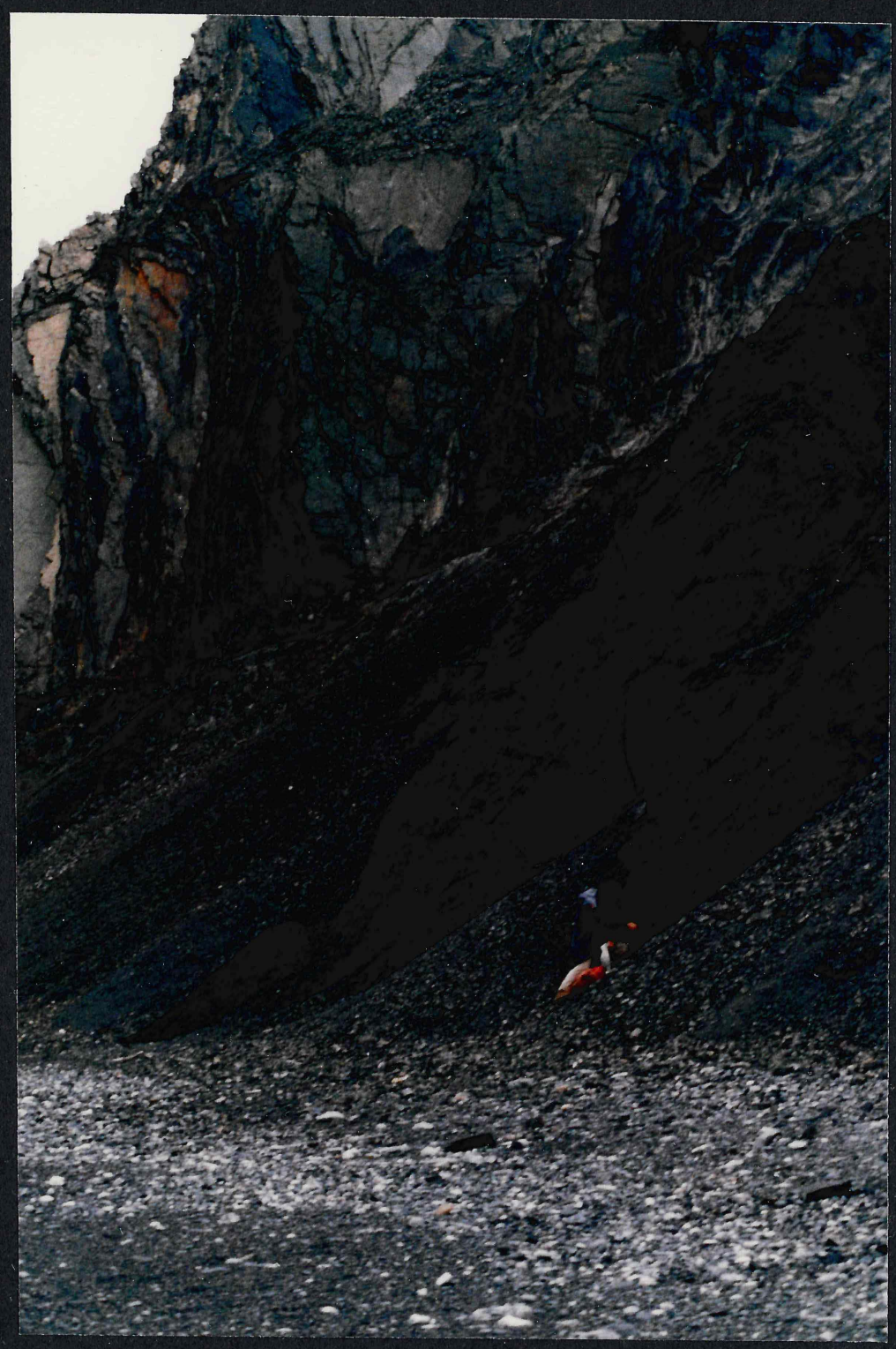


Agate Rock. View of Triassic shale. 7-17-2 $35-32 \mathrm{~N}-32 \mathrm{~W}$ 

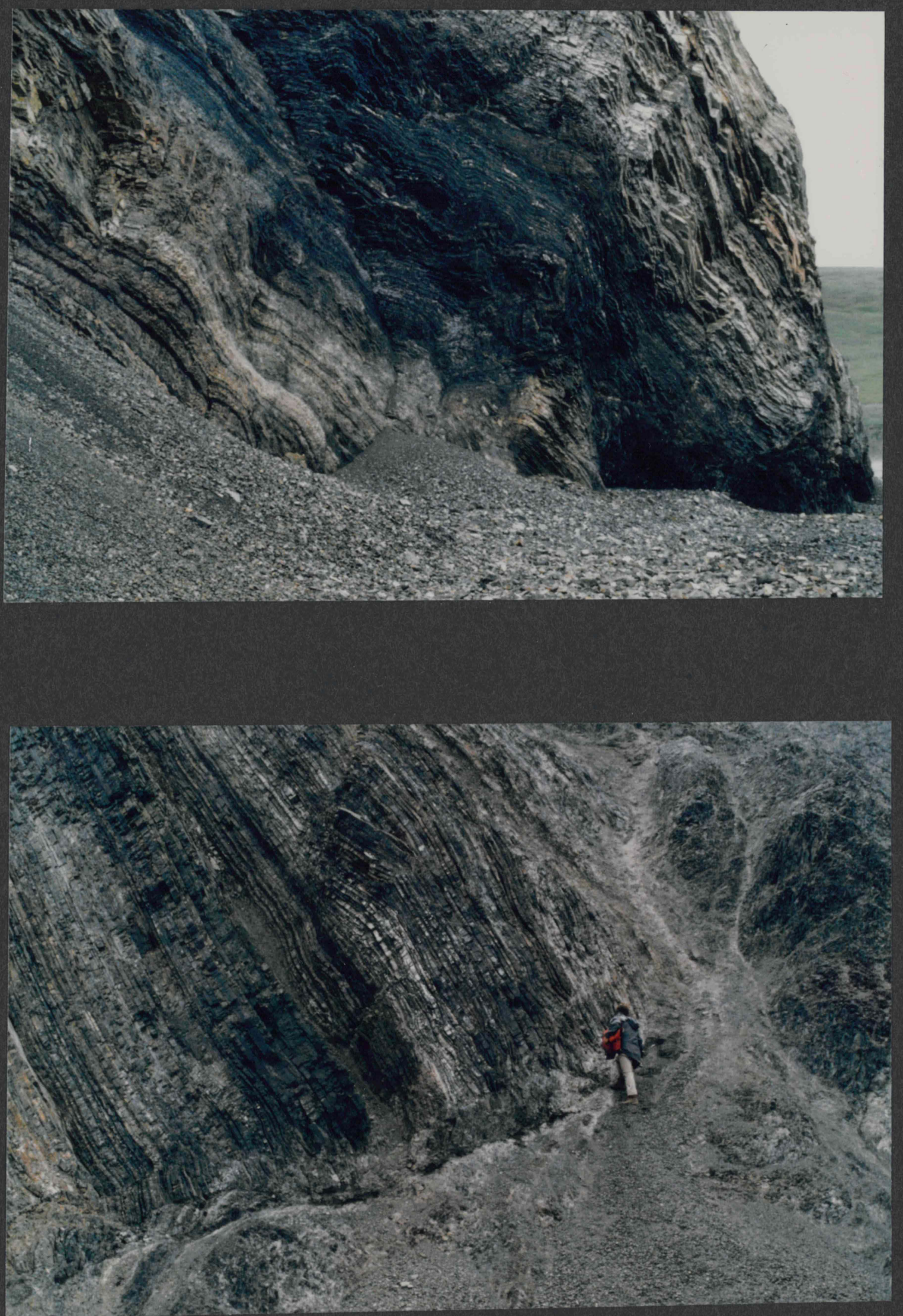
Agate Rock. Folds in dark shale and light siliceous mudstone. Permo-Triassic. 7-17-2 $35-32 \mathrm{~N}-32 \mathrm{~W}$

Agate Rock. Permo-Triassic lime and siliceous section. 7-12-2 $35-32 \mathrm{~N}-32 \mathrm{~W}$ 

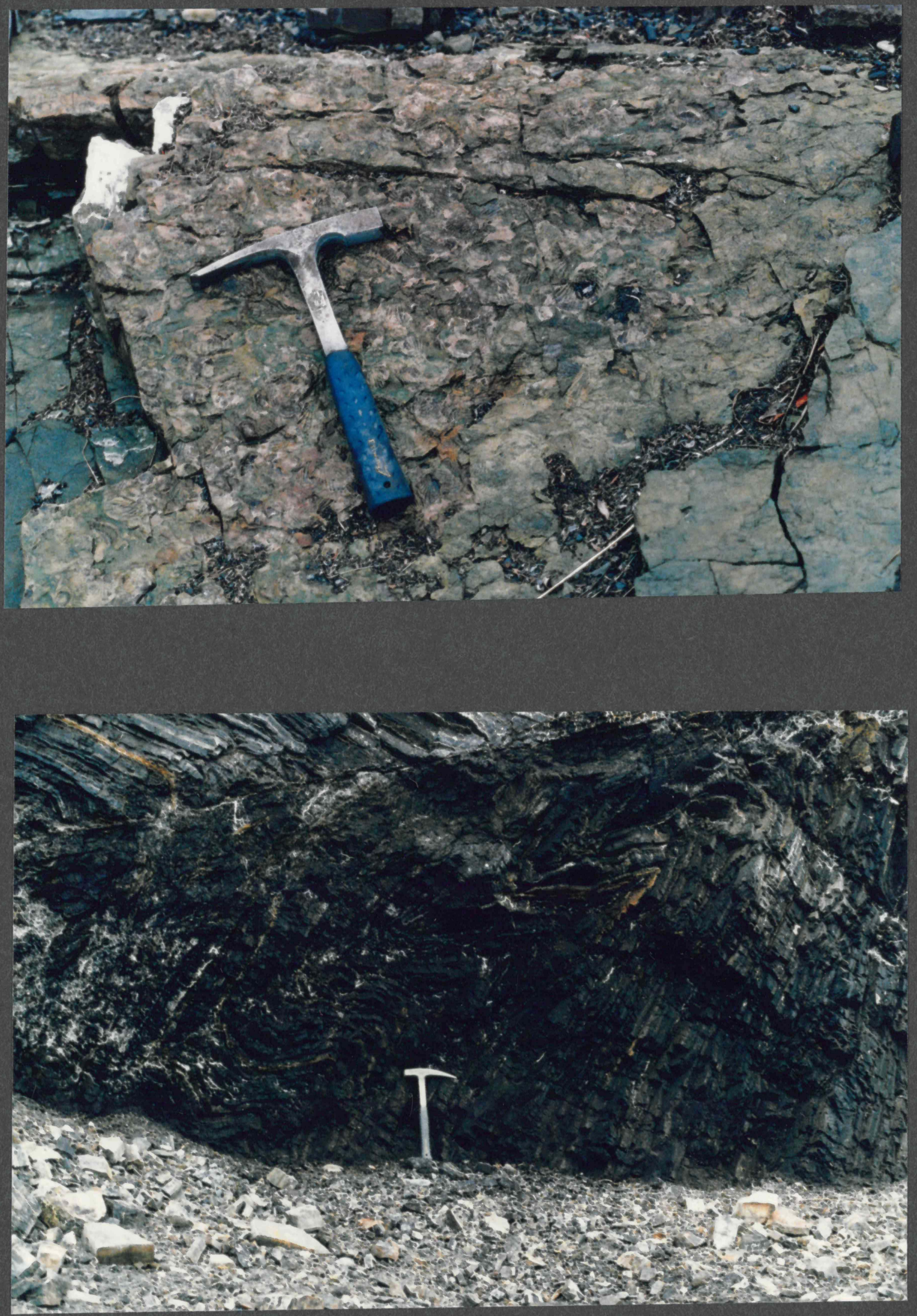
Triassic pelecypod bed.

Agate Rock. Permo-Triassic shale and chert in tight folds. 7-17-2

$35-32 \mathrm{~N}-32 \mathrm{~W}$ 


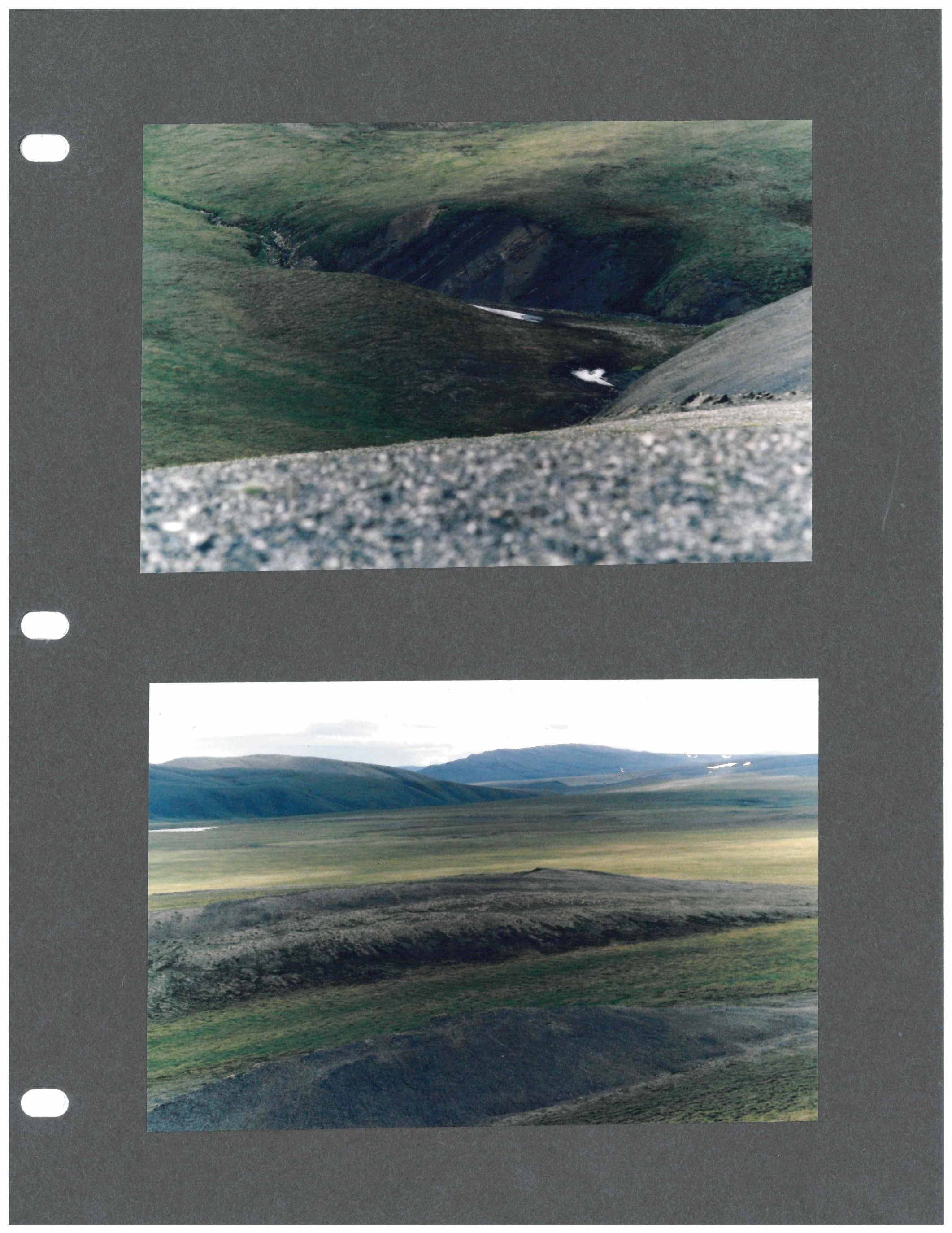


Permo-Triassic shale. $7 / 20$ lunch stop. $22-7 \mathrm{~S}-59 \mathrm{~W}$

Permo-Triassic shale. 7/20 lunch stop. 


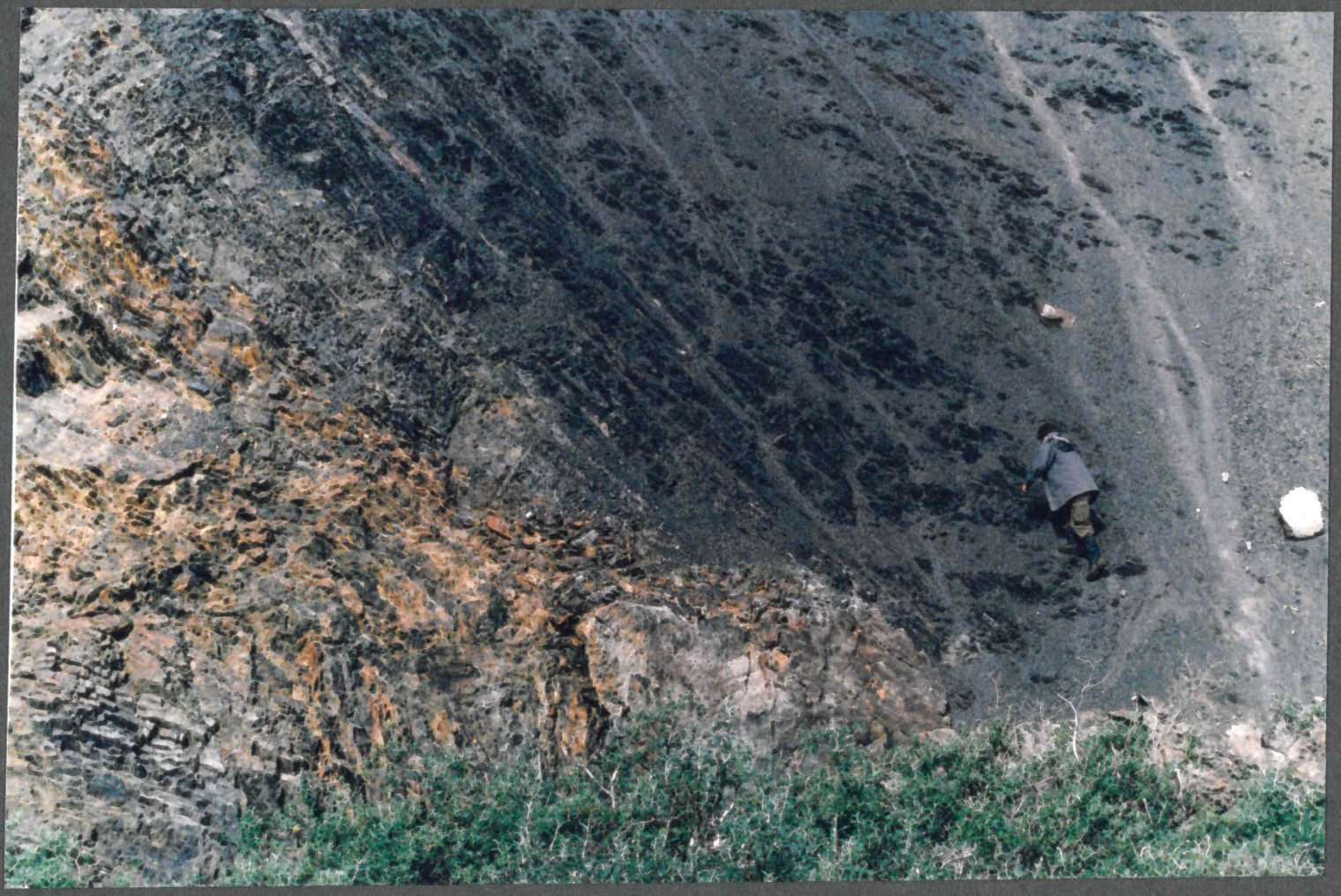



Black shale, carbonaceous, uncertain age. (? Jurassic or Triassic) 7/21-4

$\mathrm{SW} / 4$ 18-8S-58W

(?) Early Cretaceous Ogotoruk or Triassic Shublik soft black shale. 7/20-2 NE/4 8-7S-59W 


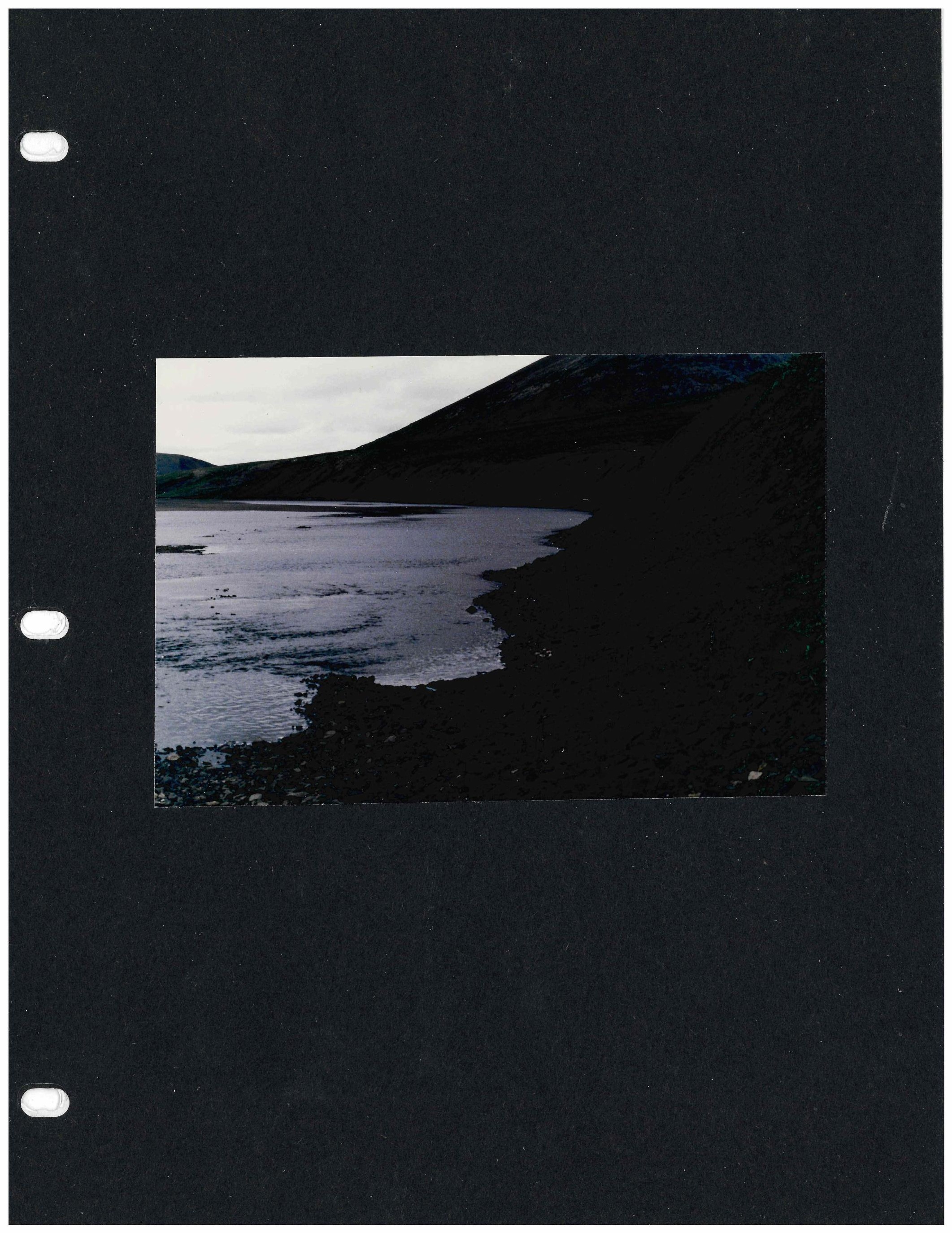


Early Cretaceous Ogotoruk stream-cut outcrop. 7/18-10 $\mathrm{NE} / 4 \quad 12-33 \mathrm{~N}-30 \mathrm{~W}$ 

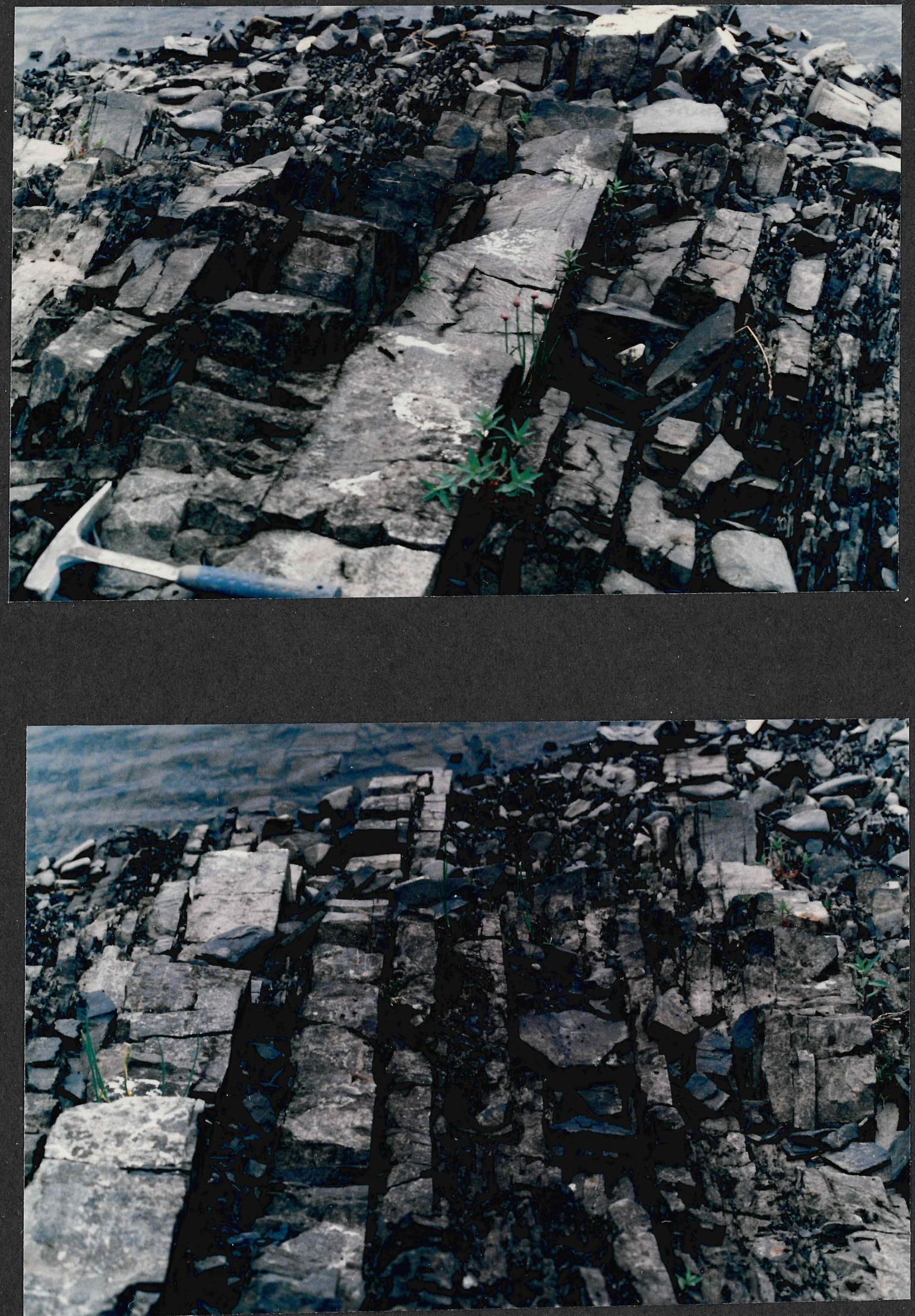
Early Cretaceous Ogotoruk sand/shale turbidite sequence. 7-18-10

$\mathrm{NE} / 4 \quad 12-33 \mathrm{~N}-30 \mathrm{~W}$

Early Cretaceous ogotoruk sand/shale turbidite sequence. $7-18-10$

$\mathrm{NE} / 4 \quad 12-33 \mathrm{~N}-30 \mathrm{~W}$ 


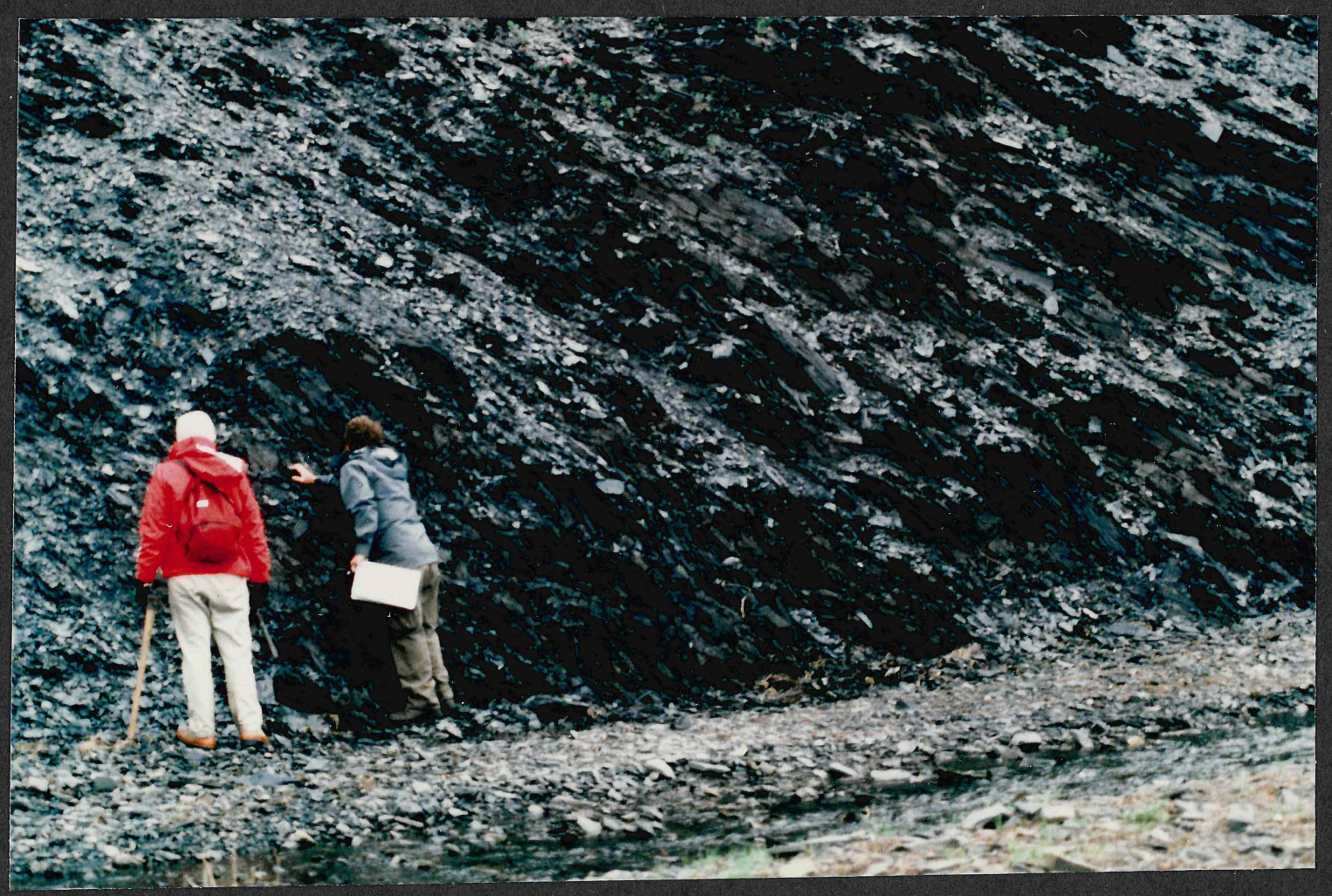


Early Cretaceous Kisimilok shale, silt and very fine-grained sandstone. 7-18-4 SW/4 $\quad 15-31 \mathrm{~N}-30 \mathrm{~W}$ 

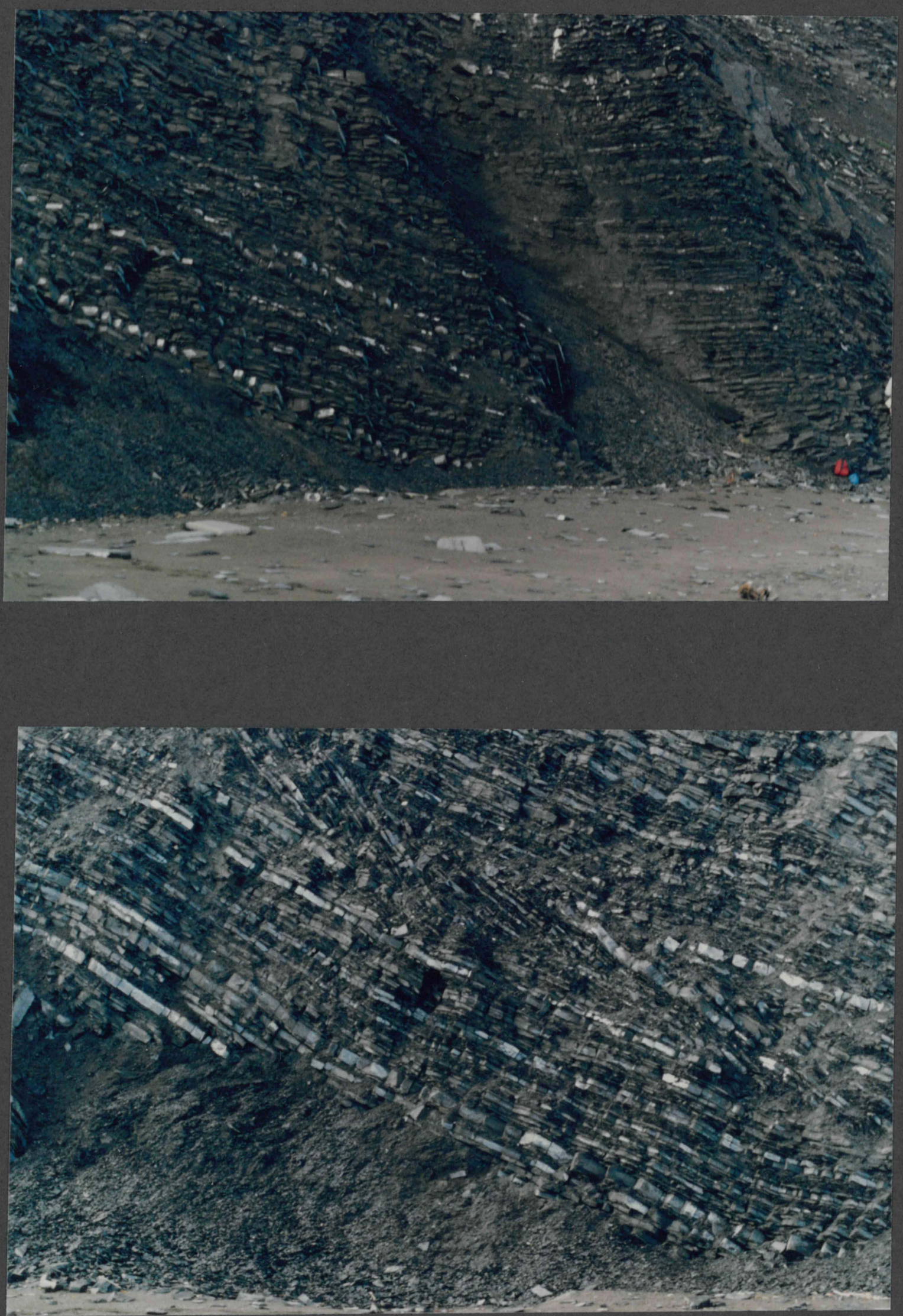
Early Cretaceous trubidite section (?). 7-20-1

$5,6-7 S-59 W$

Early Cretaceous turbidite section (?) showing

Brookian faulted folds. 7-20-1

$5,6-7 S-59 W$ 

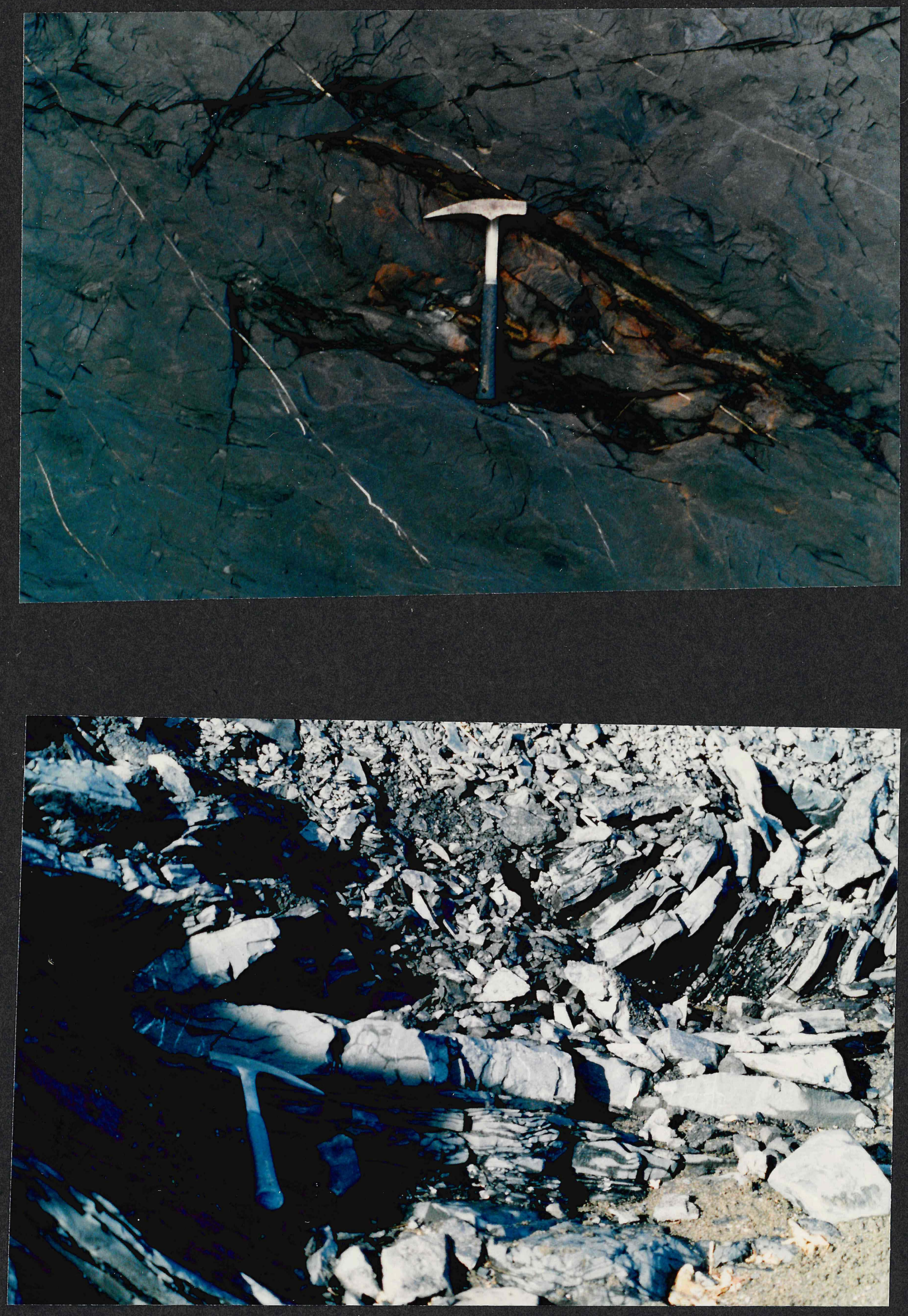
Large wood fragment in Early Cretaceous turbidite section (?). $7-20-1$

$5,6-7 S-59 w$

Early Cretaceous (?) turbidite section showing tight folds in sand and shale. 7-20-1 $5,6-7 S-59 W$ 


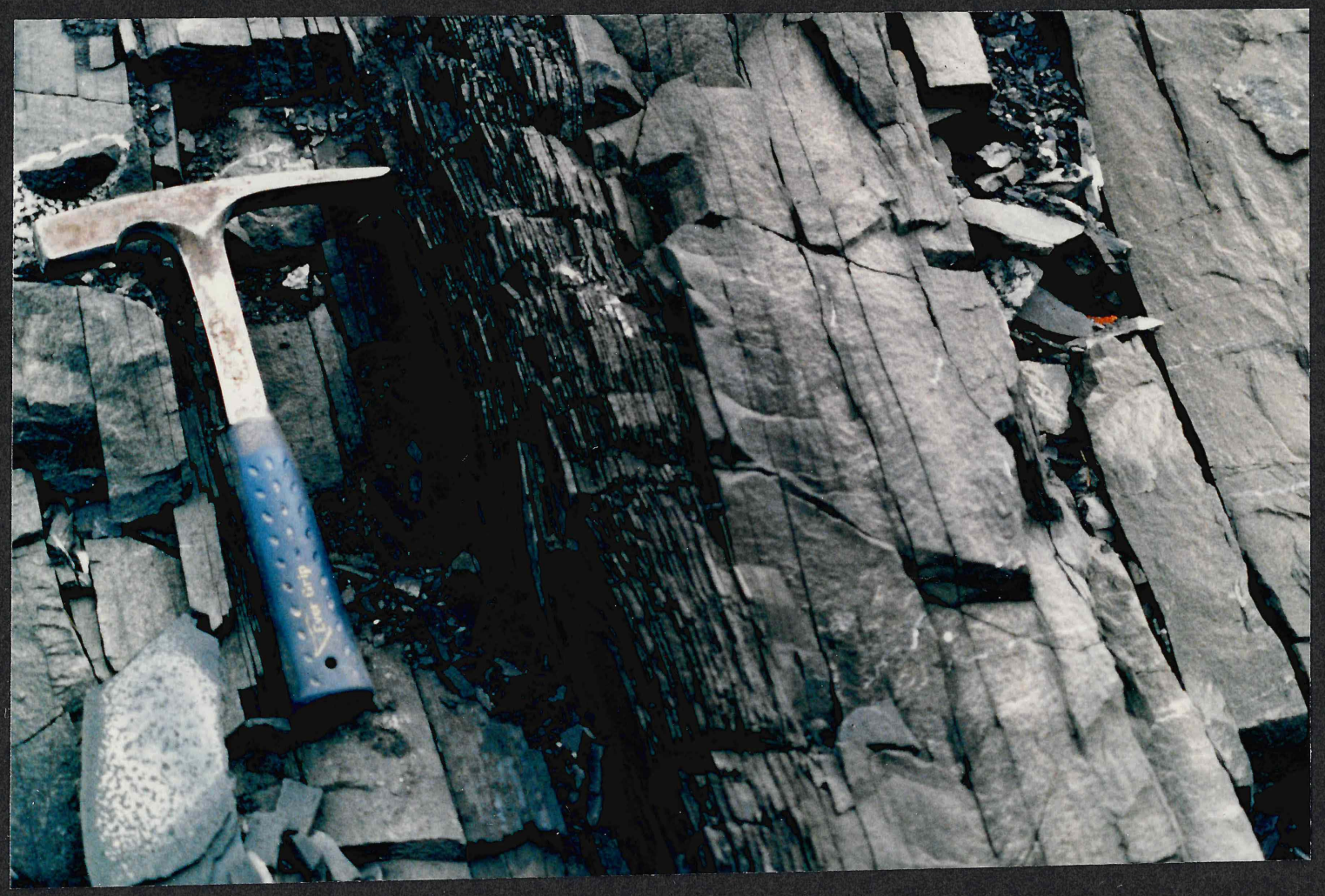


Early Cretaceous Fortress Mountain sand/shale turbidite sequence. 7-18-6 $\mathrm{NW} / 4 \quad 34-32 \mathrm{~N}-29 \mathrm{~W}$ 

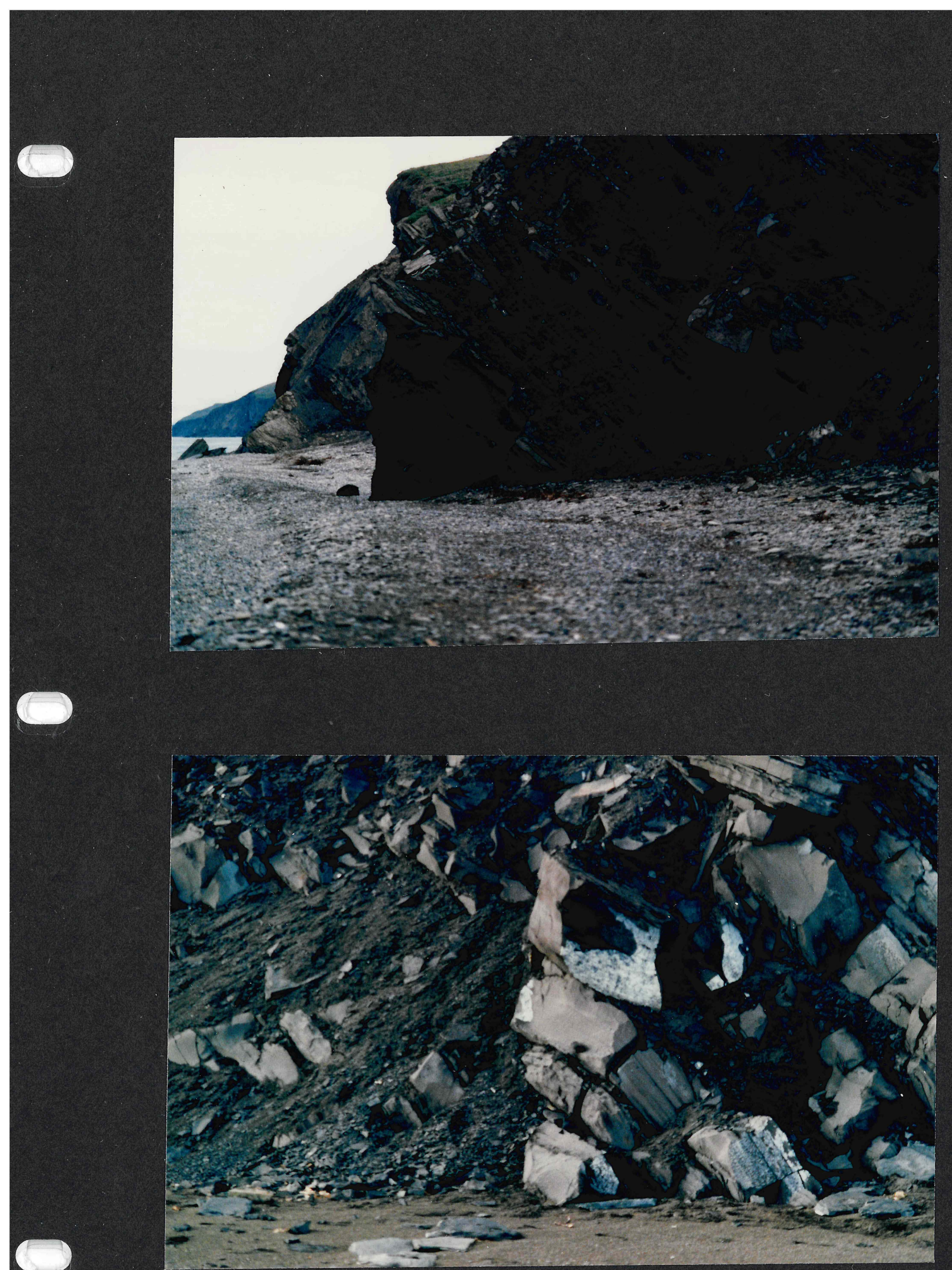
Nanushuk Group channel sandstone and shale. 7/20-8

$\mathrm{SE} / 4$ 36-6S-56W

Nanushuk Group channel sandstone with shale and coal. 7/20-8

$\mathrm{SE} / 4 \quad 36-6 \mathrm{~S}-56 \mathrm{~W}$ 

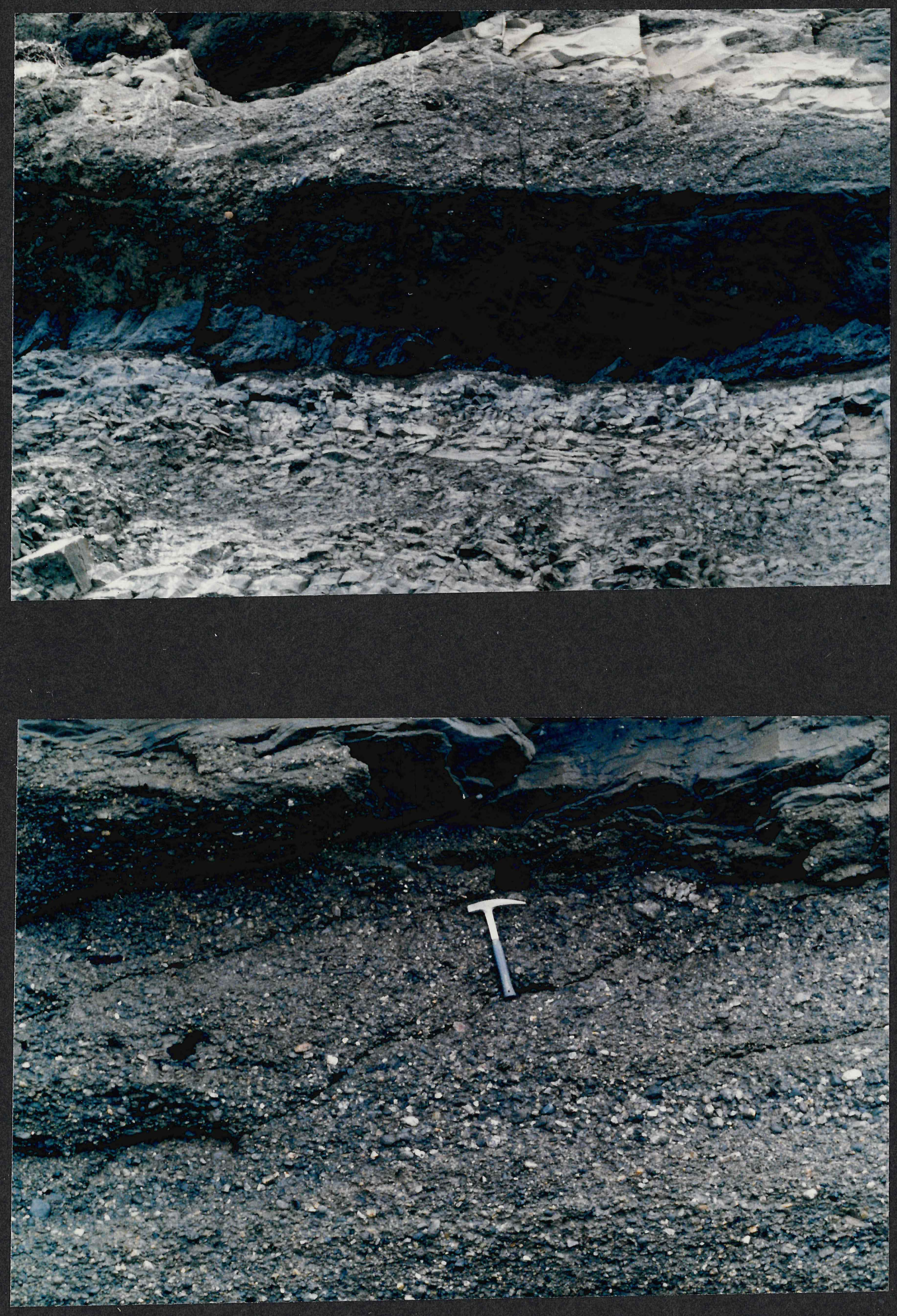
Nanushuk Group coal and thick overlying channel conglomerate with tool marks at base. 7/20-8 $\mathrm{SE} / 4 \quad 36-6 \mathrm{~S}-56 \mathrm{~W}$

Nanushuk Group coarse channel facies. 7/20-8 $\mathrm{SE} / 4 \quad 36-6 \mathrm{~S}-56 \mathrm{~W}$ 
Close up view of Exxon core rig and Jon Bloom, geologist. 
Jon Vaitl and F. X. O'Keefe at

north shore Chukchi Sea, Lisburne Peninsula. 

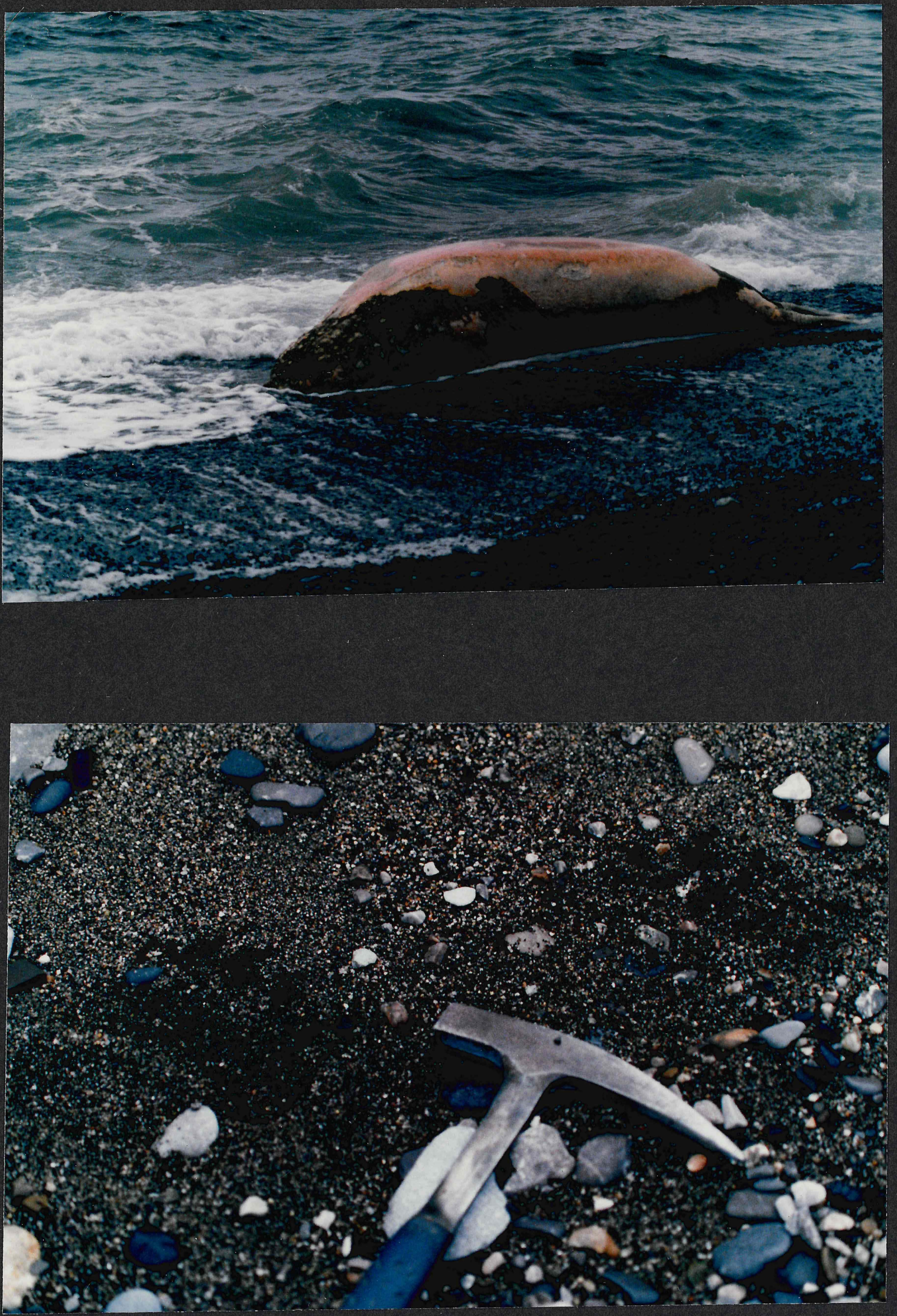
Dead headless walrus.

Close-up of bear tracks on gravel beach. 

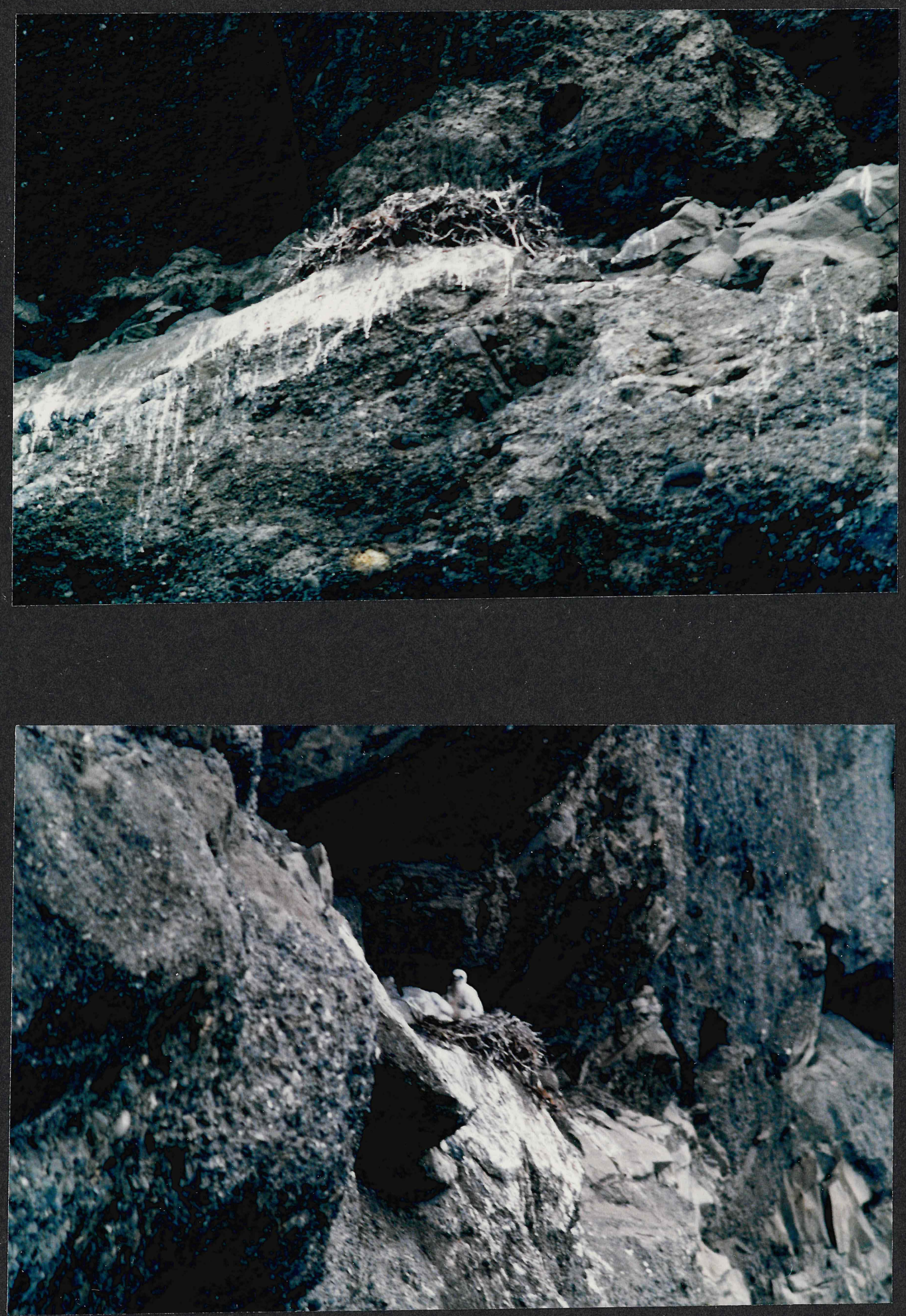
Eagle birdnest on Nanushuk Group. 7/20-8

Nanushuk Group with downy baby eagles in nest. 7/20-8 

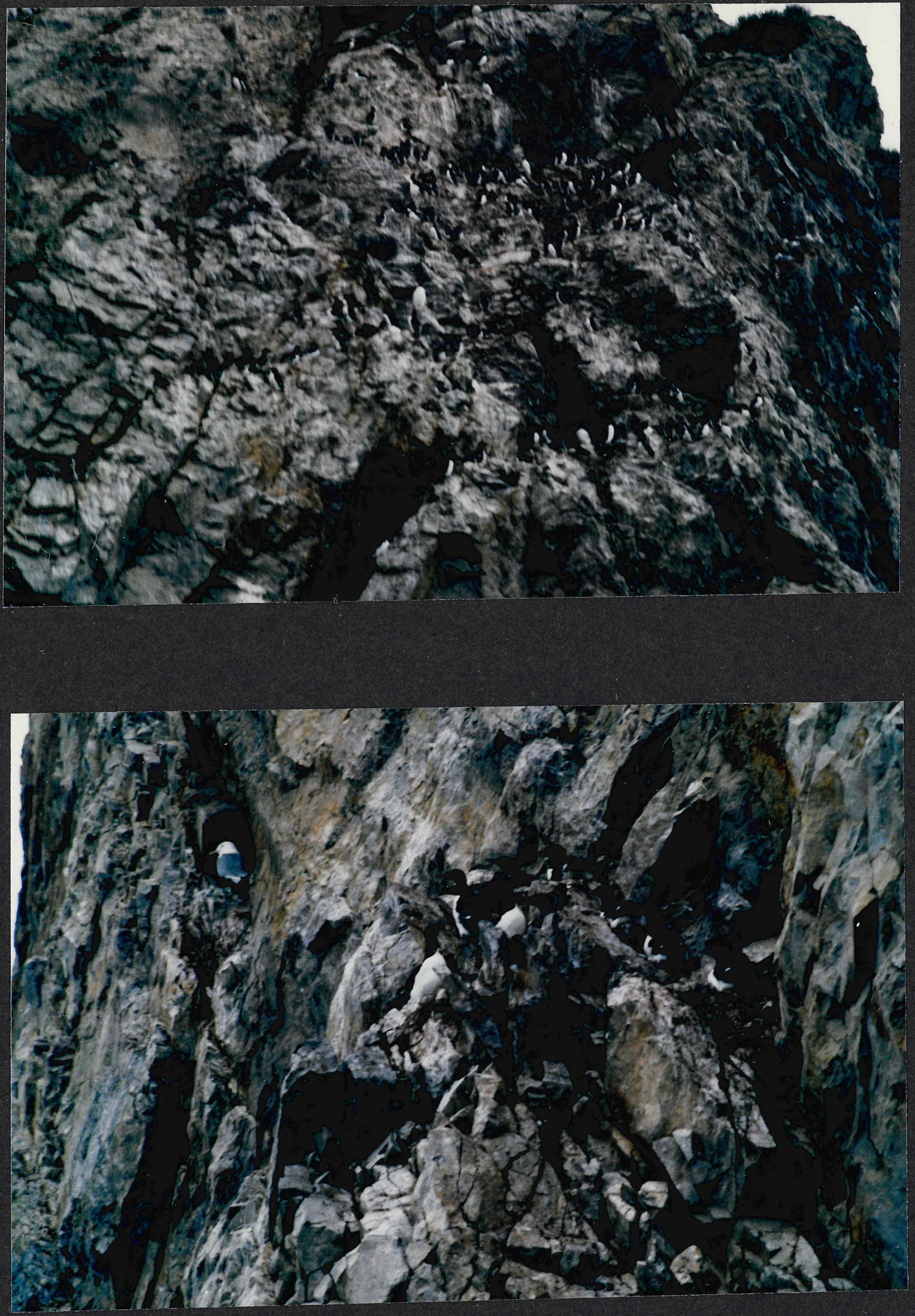
Birds on cliff.

Birds on cliff. 


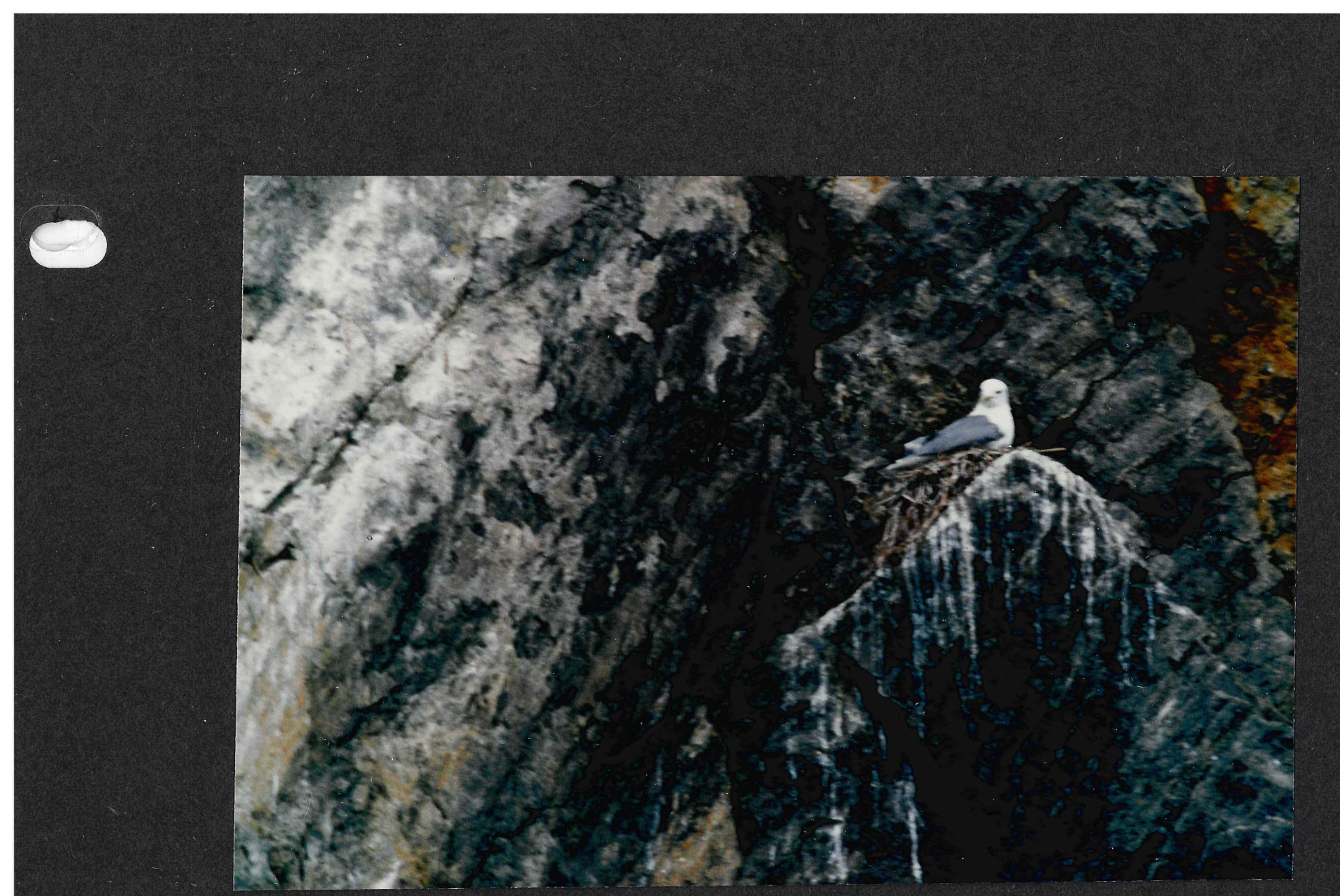


Seagul1.

Puffin. 


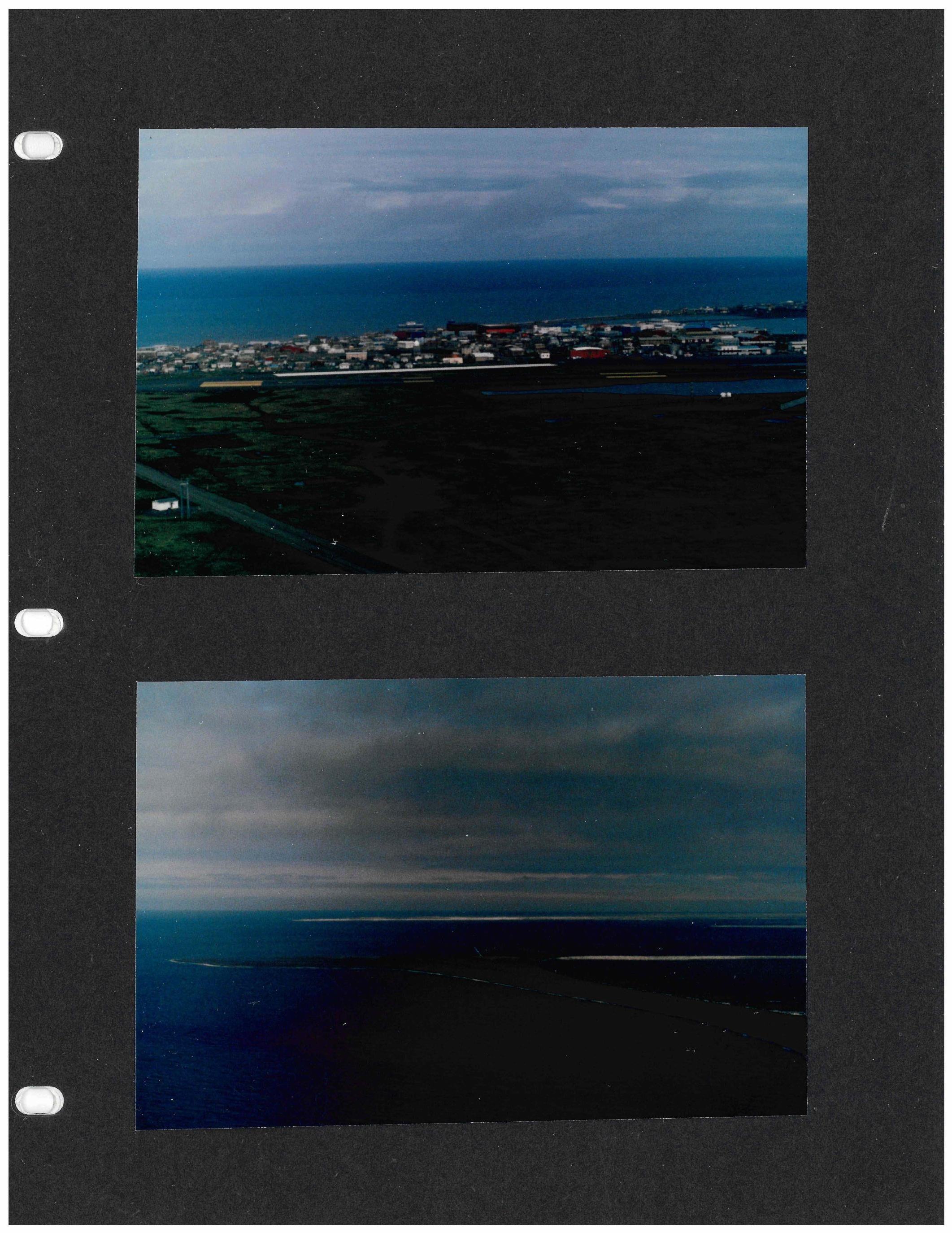


Barrow, Alaska.

Point Barrow, Alaska. 

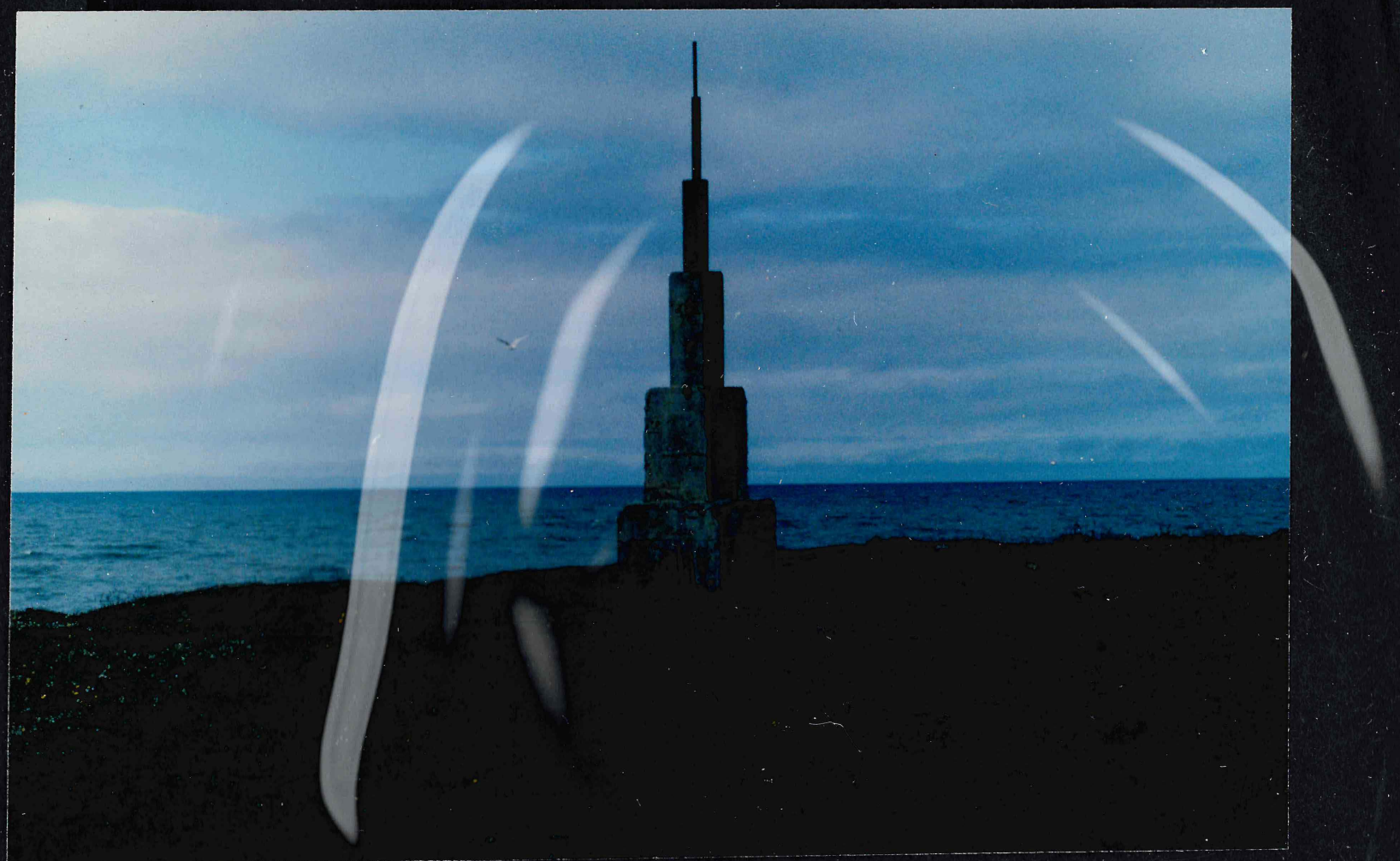

1

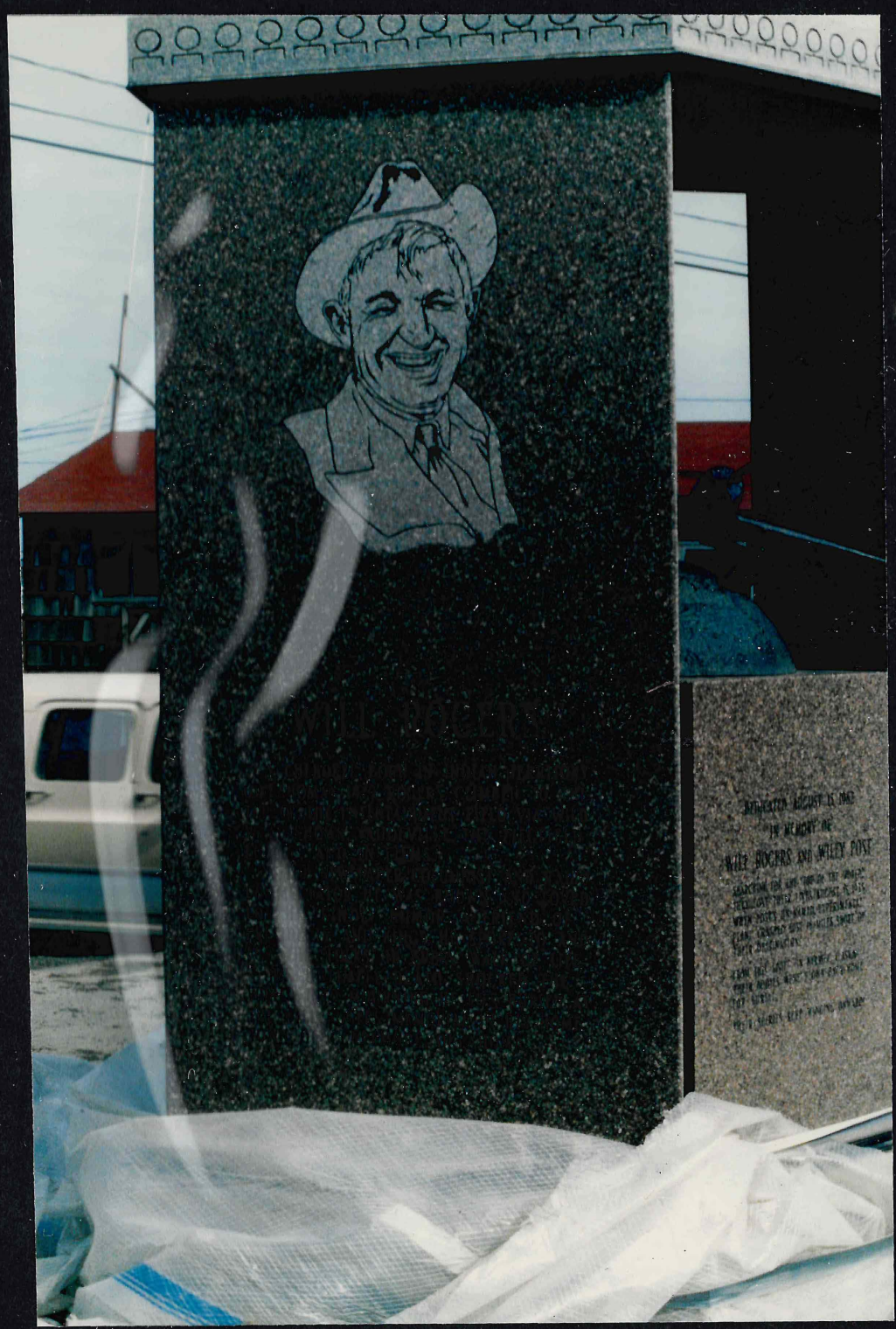


Will Rogers Memorial, south of Barrow, Alaska.

Will Rogers/Wiley Post Memorial, Barrow, Alaska. 


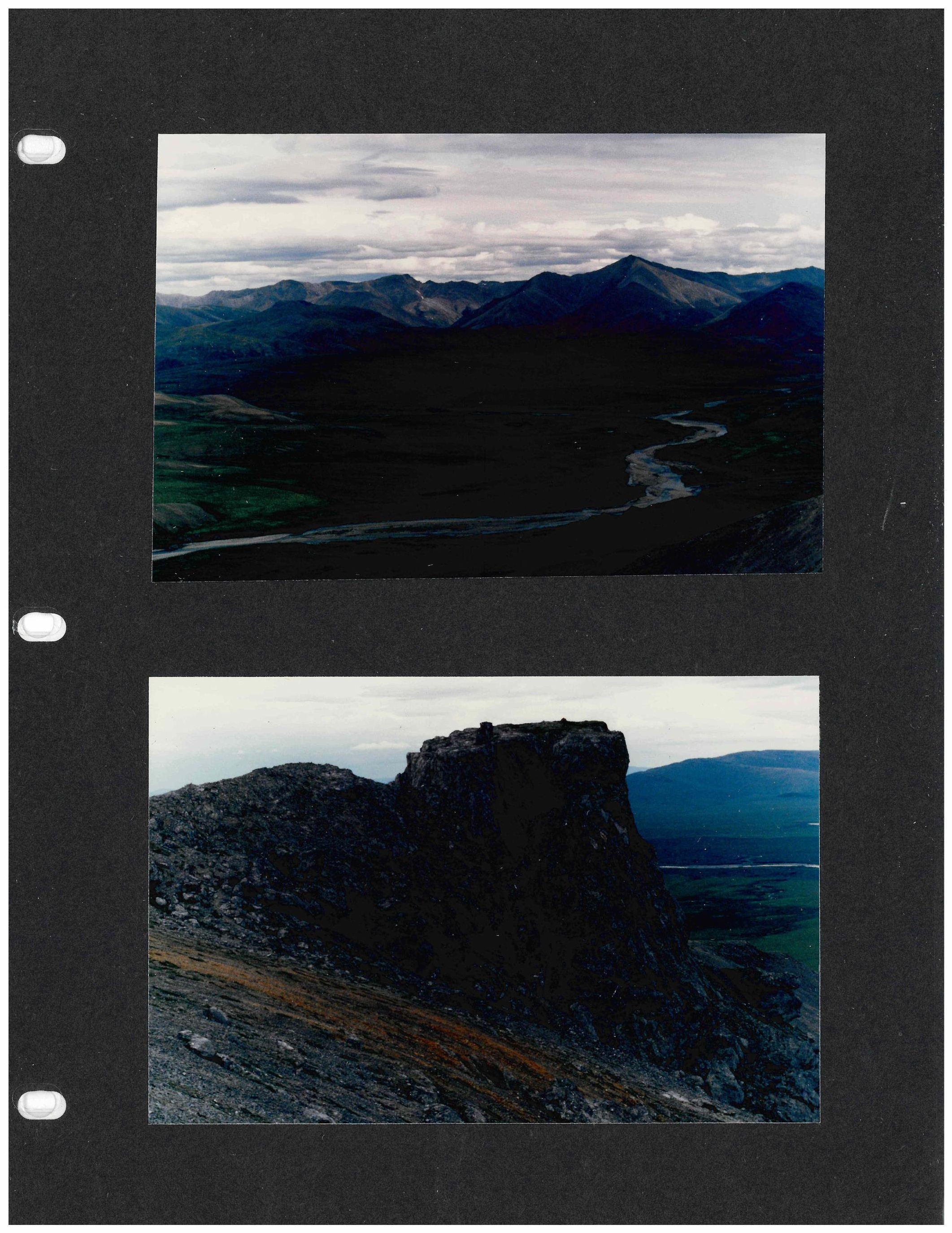


De Long Mountains.

Devonian Baird Group limestone, De Long Mountains. 7/23-7

T31N-R21W 

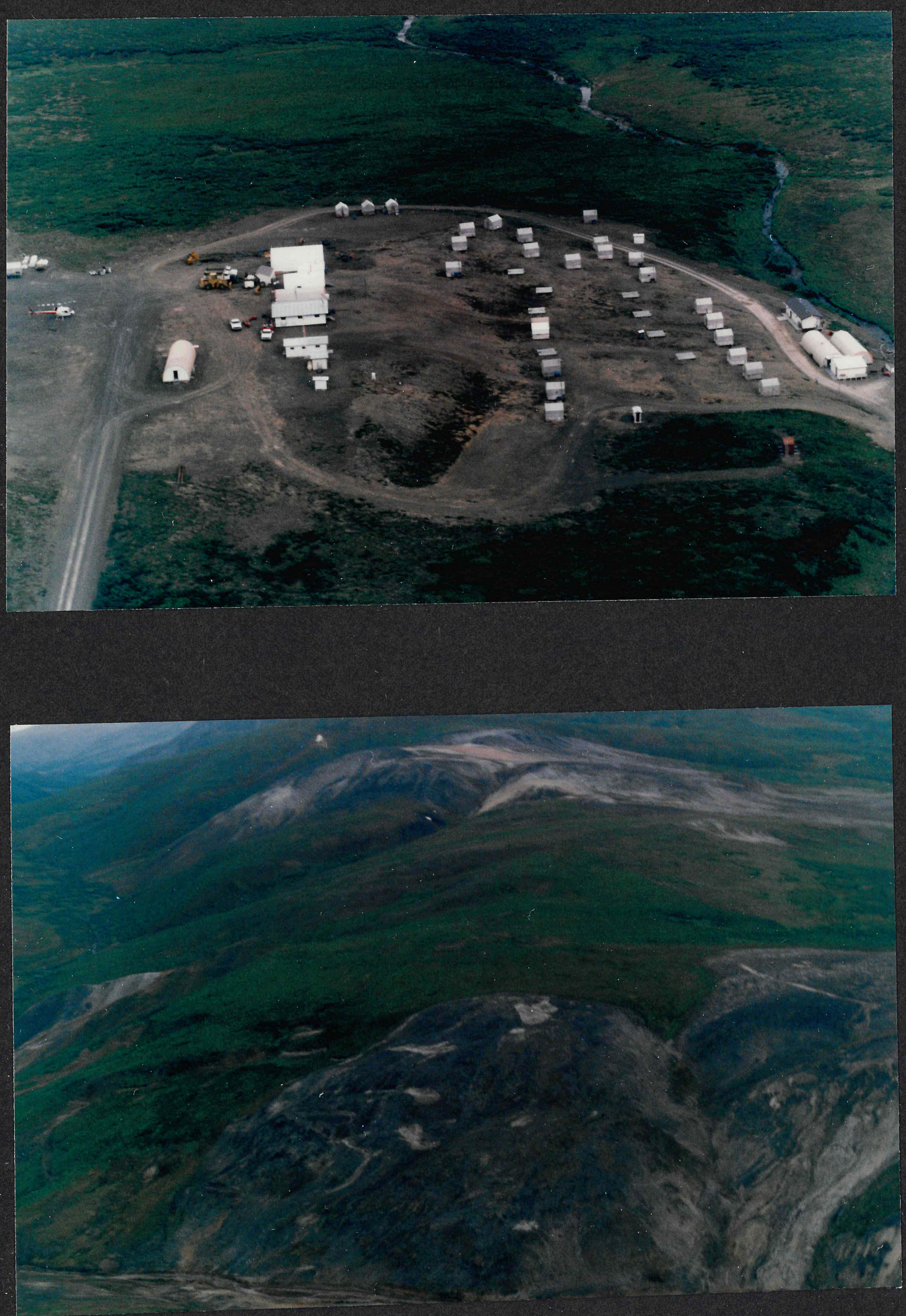
Red Dog Mine camp, De Long Mountains.

Red Dog Mine, De Long Mountains. 


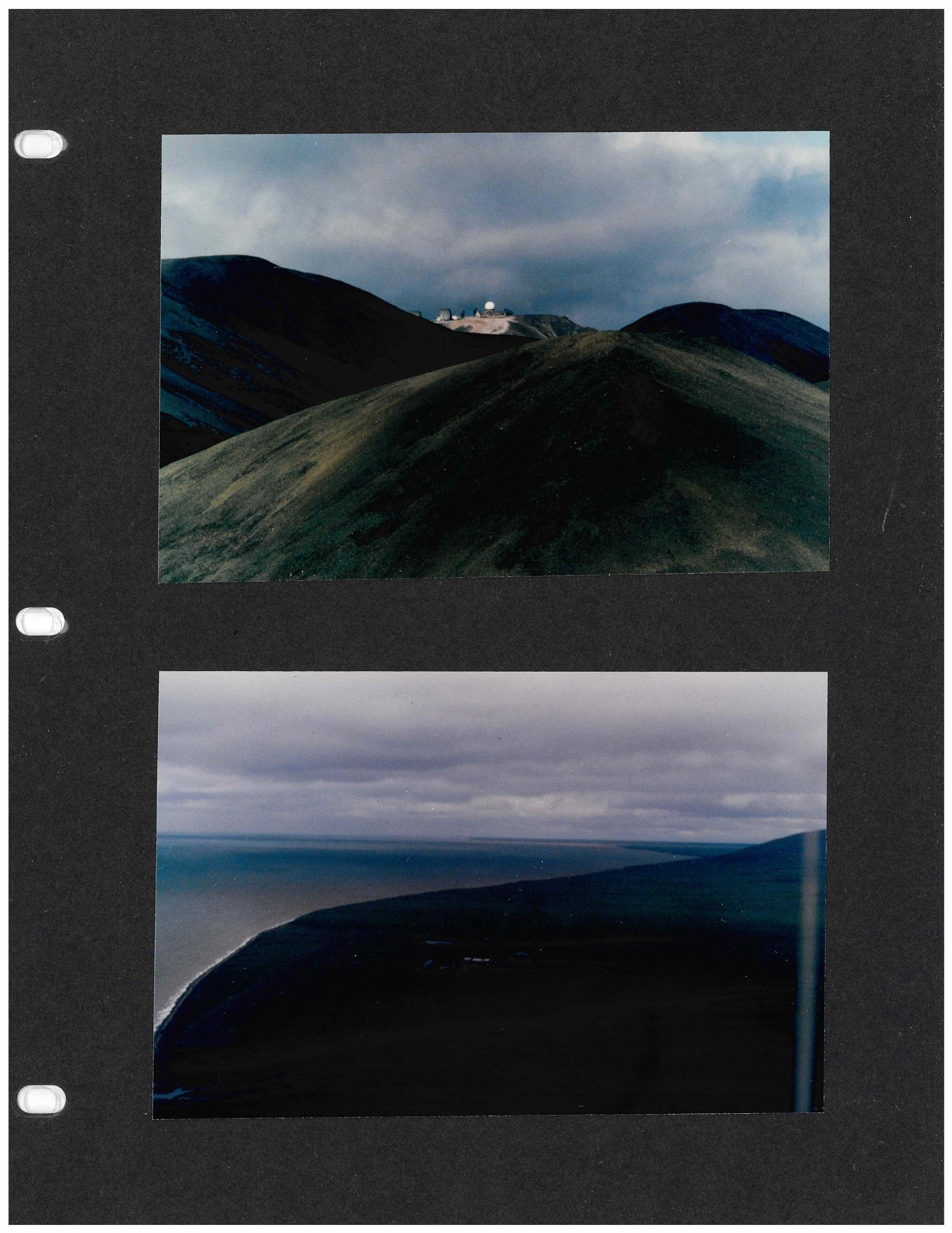


Cape Lisburne DEW Iine radar station.

Cape Sabine DEW line station. 


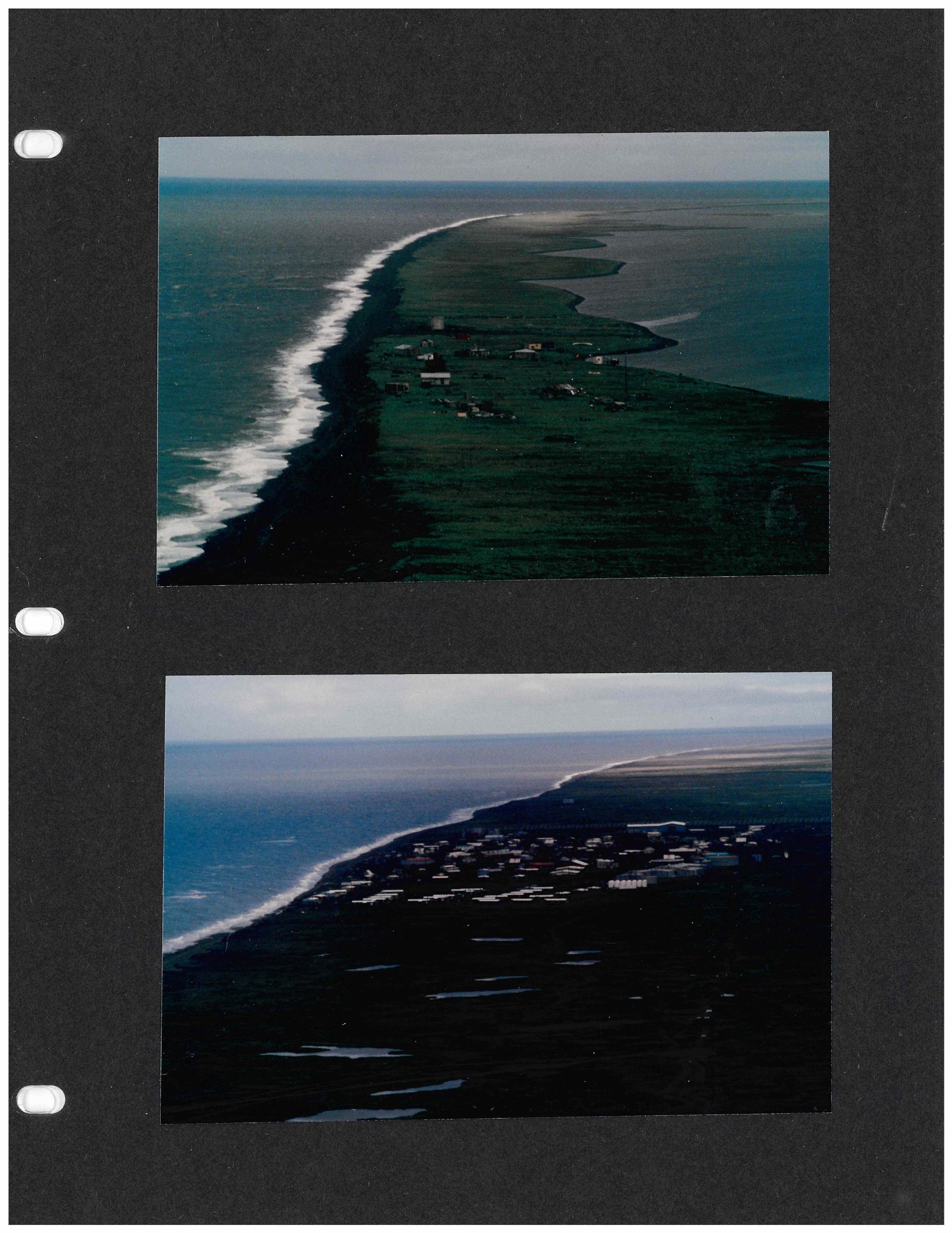


Point Lay Village.

Wainwright Village. 